\title{
Experiences of Registered Nurses as Managers and Leaders in Residential Aged Care Facilities
}

\author{
Drew Dwyer, BASS, BSN, MRCNA, QMACA \\ Master of Clinical Science \\ The Joanna Briggs Institute, Faculty of Health Sciences \\ The University of Adelaide
}

July 2011 


\section{Thesis declaration}

This work contains no material which has been accepted for the award of any other degree or diploma in any university or other tertiary institution to Drew Dwyer and, to the best of my knowledge and belief, contains no material previously published or written by another person, except where due reference has been made in the text.

I give consent to this copy of my thesis, when deposited in the University Library, being made available for loan and photocopying, subject to the provisions of the Copyright Act 1968.

I also give permission for the digital version of my thesis to be made available on the web, via the University's digital research repository, the Library catalogue, the Australasian Digital Theses Program (ADTP) and also through web search engines, unless permission has been granted by the University to restrict access for a period of time.

Signature:

Date: April 2012 
ACKNOWLEDGMENTS

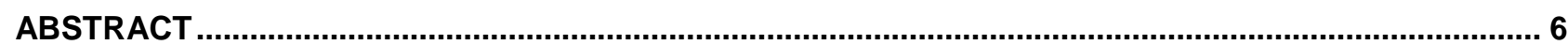

BACKGROUND .

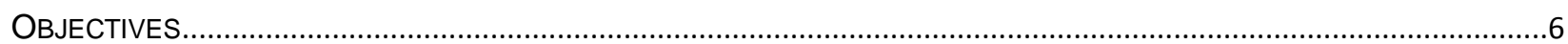

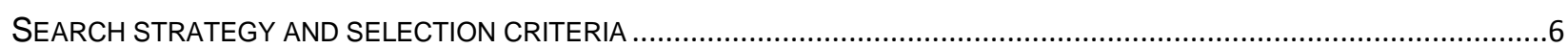

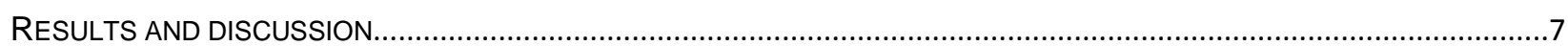

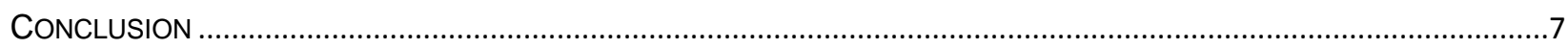

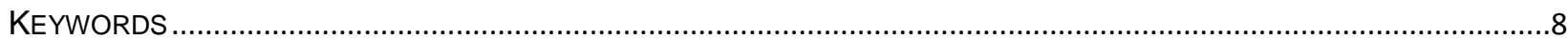

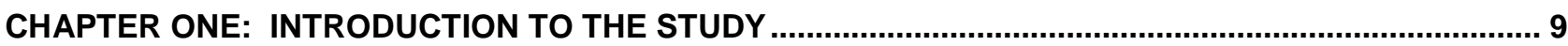

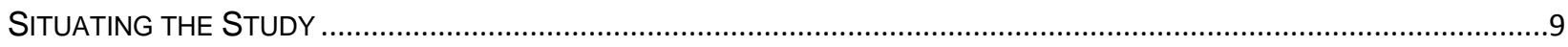

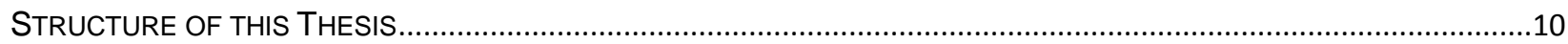

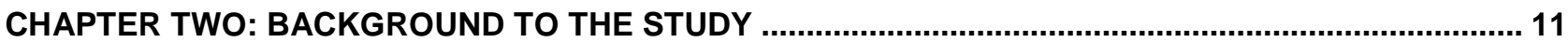

FACTORS CONTRIBUTING TO THE GLOBAL SHORTAGE OF NURSING PROFESSIONALS ...........................................15

FACTORS CONTRIBUTING TO THE GLOBAL SHORTAGE OF NURSING PROFESSIONALS IN AGED CARE ......................15

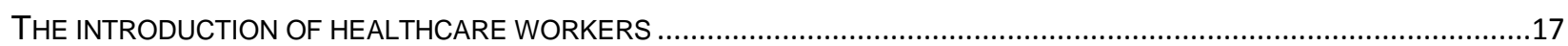

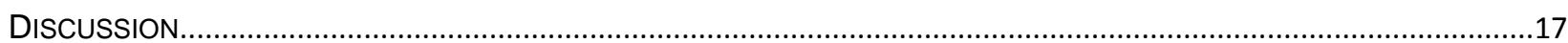

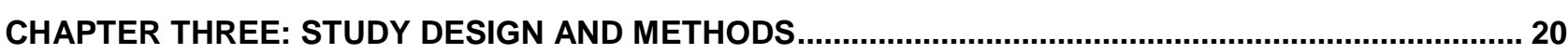

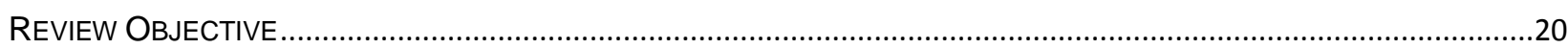

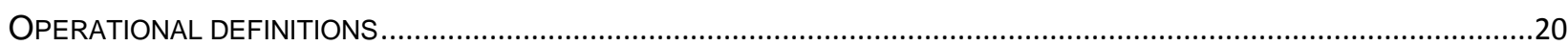

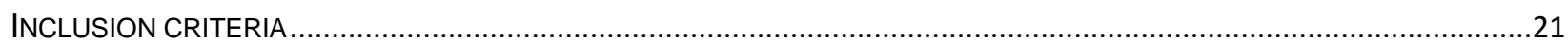

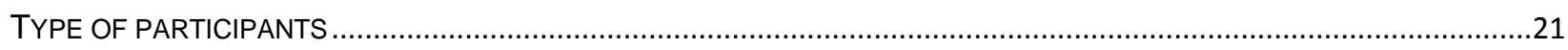

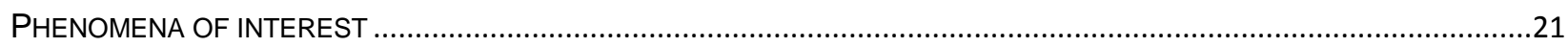

TYPE OF STUDIES

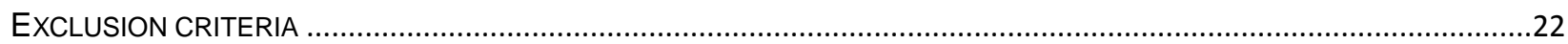

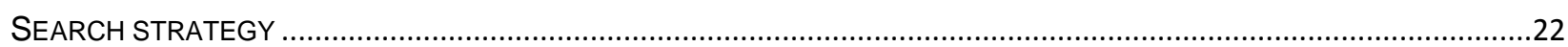

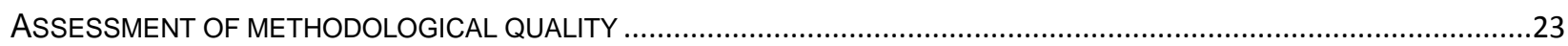

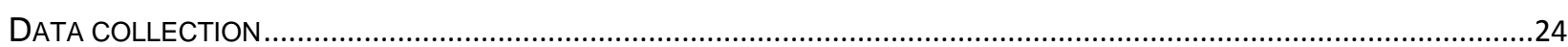

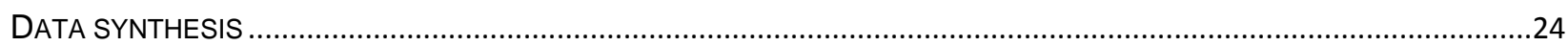

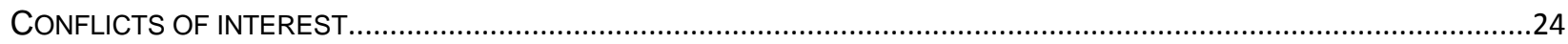

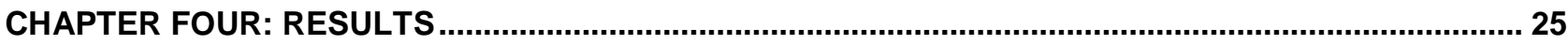

SEARCH RESULTS

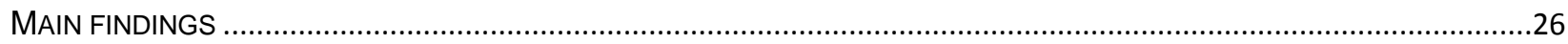

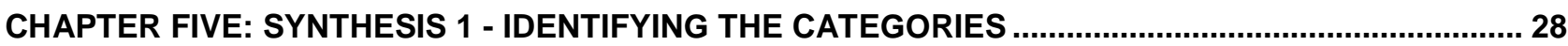

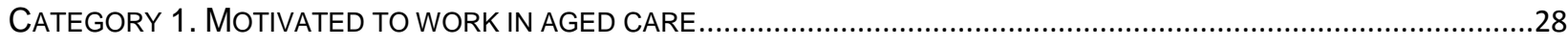

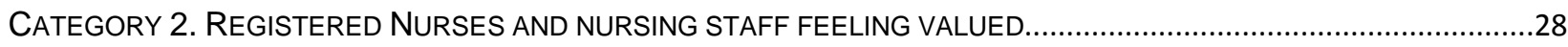

CATEGORY 3. NOT ENOUGH PROFESSIONAL EDUCATION FOR THE RN TO REMAIN CONFIDENT ................................29

CATEGORY 4. ORGANISATIONAL BARRIERS INTERFERE WITH THE QUALITY OF CARE TO INDIVIDUALS, SERVICE

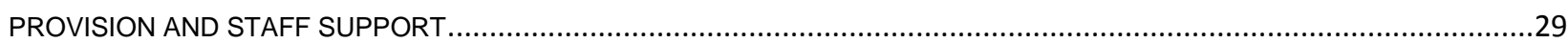

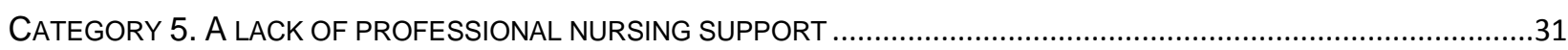

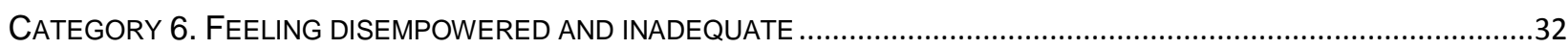

CATEGORY 7. THE INDUSTRY DOES NOT RESPECT THE WORKFORCE ….........................................................

CATEGORY 8. GERIATRIC NURSING IS A SPECIALISED FIELD THAT WARRANTS ITS OWN PROFESSIONAL IDENTITY ...33

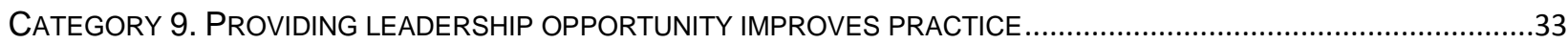

CATEGORY 10. RNS FEEL THEY ARE NOT UP TO STANDARD AND WORRY ABOUT ACCOUNTABILITY..........................35

CATEGORY 11. NURSES FEEL THAT AGED CARE WORK IS REFLECTIVE OF HAVING A POOR COMPETENCY ................35

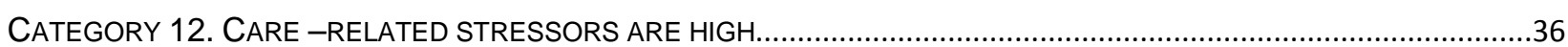




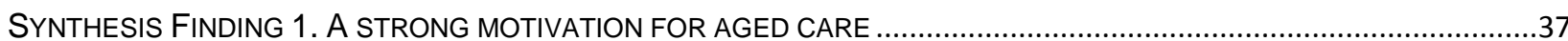

SYNTHESIS FINDING 2. EDUCATION IN CLINICAL LEADERSHIP AND MANAGEMENT IS NEEDED ...................................37

SYNTHESIS FINDING 3. A SPECIALISED CARE AREA THAT REQUIRES IMPROVED RECOGNITION...............................39

SYNTHESIS FINDING 4. ORGANISATIONAL BARRIERS HAVE A NEGATIVE IMPACT ON CARE OUTCOMES AND

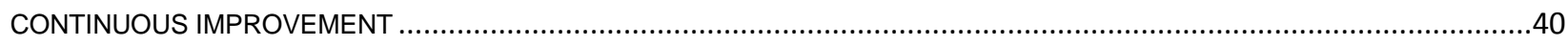

SYNTHESIS FINDING 5. POSITIVE AND PROACTIVE CARE MODELS IMPROVE MORALE AND PRODUCTIVITY .................41

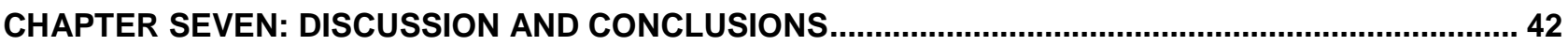

IMPROVING THE RECRUITMENT RETENTION AND CAPACITY OF NURSES ENTERING THE AGED CARE AND GERIATRIC

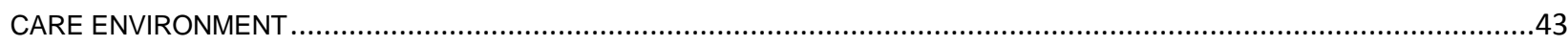

EMPLOYERS AND POLICY MAKERS SHOULD BE AWARE THAT NURSES IN AGED CARE AND GERIATRICS HAVE A STRONG MOTIVATION TO WORK IN THE AGED CARE SECTOR AND WANT TO BE VALUED BY THE COMMUNITY. . .43 EDUCATIONAL PATHWAYS AND PROGRAMS ARE NEEDED TO IMPROVE THE PROFESSIONAL PRACTICE AND CONTINUOUS DEVELOPMENT OF NURSES WITH CLINICAL AND LEADERSHIP SKILLS.....

AGED CARE PROVIDERS AND HEALTHCARE POLICY MAKERS SHOULD UNDERSTAND THAT AGED CARE AND GERIATRICS IS A SPECIALISED AREA OF HEALTHCARE THAT WARRANTS ITS OWN RECOGNITION IN PROFESSIONAL PRACTICE.

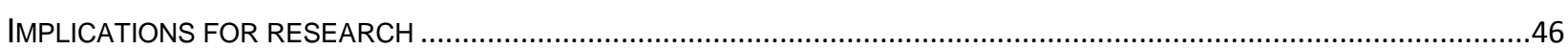

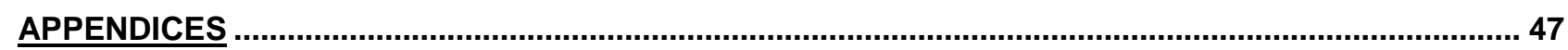

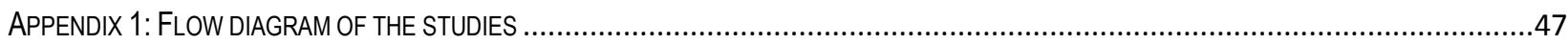

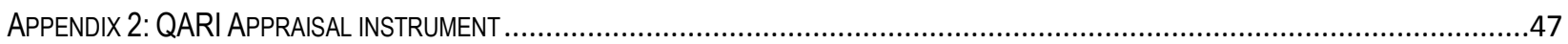

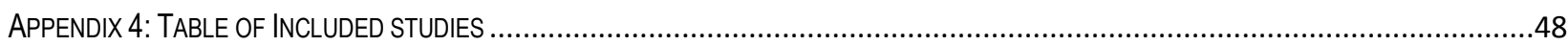

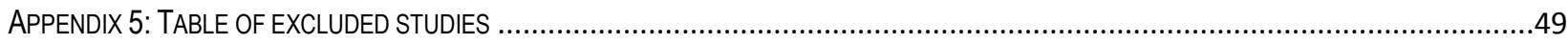

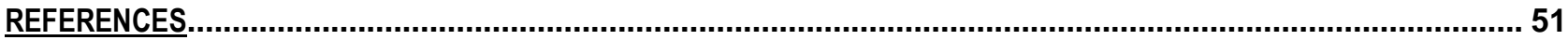




\section{Acknowledgments}

I want to take this opportunity to thank the people who have motivated and guided me through the process of learning this research topic at a higher degree level and assisting me in focusing on the subject and achieving the necessary outcomes.

Thank you to Professor Alan Pearson and the entire JBI team. I appreciate them for providing me with their time and assisting me in finding the focus of higher degree learning in the past 2 years.

Dr Aye Aye Gyi was my principal supervisor and mentor during the preparation of this thesis. I greatly appreciated her guidance, encouragement and support. Her motivation was a driving force.

Dr Leonie Mosel Williams, as my associate supervisor for distance students, provided her knowledge and nursing expertise in a timely and supportive way. She guided me in the subject knowledge and specialised nursing focus on the topic. Without her input I would never have finished the project in time.

Thank you Dr Rie Konno for your assistance and input at times when nursing acumen was needed in residential school studies, and preparing the systematic review.

My special thanks to my wife Raeleen for her support in all she does to encourage the vision and passion within me that keeps the oil in my lantern burning bright. Thanks to my two children, Masyn and Dane for being patient and supportive during long periods of time away, and being separated due to focusing on study.

Finally, my supportive office staff who have managed things around my schedules, I thank you as well. 


\begin{abstract}
Background

The phenomenon of an increasing ageing population is being experienced globally, causing challenges to change and improve residential models of care and provide services that meet the growing population of older people. The role of the registered nurse is considered crucial to the clinical governance and management of care given to the elderly in residential care settings. Registered nurses who work in the role to-date have made many changes in their practice so that they can work using a multidisciplinary approach to care; however, no systematic review has to date examined the registered nurses' experiences in leadership and management roles.
\end{abstract}

\title{
Objectives
}

The objective of this review was to critically appraise, synthesise and present best available evidence on the experiences of registered nurses as clinical leaders and managers in residential aged care facilities.

\section{Search strategy and selection criteria}

This review considered qualitative research papers that addressed the experiences of registered nurses as clinical leaders and managers in residential aged care facilities. Participants of interest were registered nurses, nurse leaders, nurses holding registration and/or regulation under a board of nursing, nurses working in residential aged care and long-term care facilities. The diversity and use of language to describe nurses' roles and models of care for the elderly care environment were considered in the review.

The search strategy was extensive and sought to find both published studies and papers, limited to the English language and published between January 1997 and February 2011. This period of time was chosen because 1997 was the International Year of the Older Person and much reform in care for the aged had been established prior to this date.

Each paper was assessed by two independent reviewers for methodological quality prior to inclusion in the review using an appropriate critical appraisal instrument from the Joanna Briggs Institute System for the Unified Management, Assessment and Review of 
Information (SUMARI) package. As both reviewers were in agreement on all studies included, a third reviewer was not required.

\section{Results and discussion}

A total of eight qualitative papers were included in the review. The majority of papers examined the experiences of nurses' leadership styles and the management characteristics within their organisations. The qualitative papers were analysed using The Joanna Briggs Institute-Qualitative Assessment and Review Instrument (QARI). The process of meta-synthesis embodied in this program involves the aggregation or synthesis of findings or conclusions. There were 40 findings identified from the literature, which were then synthesised into 12 categories. These categories were then synthesised to establish the final findings. Five synthesised findings were derived with key themes related to education, professional nursing development, positive attitudes to aged care and the need for a supportive environment.

\section{Conclusion}

Registered nurses employed in the aged care environment show a strong motivation to work in this field and aim to provide the best outcomes in nursing the elderly. Geriatric nursing is considered to be a specialised and complex area of healthcare by the nursing profession and the individual nurses who practice in this field of endeavour. Nurses experience a lack of professional support in clinical decision-making and limited collaboration from allied health and medical colleagues. It is evident that specific education focused in clinical leadership and health team management is lacking, yet this is an area of key performance for the registered nurse in elder care residential models. There is no current structured pathway of learning and development for nursing careers in aged care. Although globally the nurse is considered the leading clinician in daily care needs, the role is not clearly defined and furthermore clouded by operational boundaries and expectations of nurses. Nurses identify with their leadership role in residential aged care, and experience paradoxical feelings of being valued by the clients and yet at the same time devalued by the system. Substantial organisational barriers prevent continuing education and skills development for nurse leaders in the aged care environments. Organisations are more concerned with compliance and governance relating to service delivery than the 
challenges and barriers the care team faces by trying to deliver quality person-centered care and adequate time management.

\section{Keywords}

"leadership", "management", "nursing homes", "residential facilities", "long-term care facilities", "nurse", "registered nurse", "experience", "perception", "aged care facility", "qualitative", "systematic review". 


\section{Chapter One: Introduction to the Study}

\section{Situating the Study}

This study examines the literature on the experiences of registered nurses as clinical leaders and managers working in residential aged care facilities. My interest in this particular subject relates to my professional role and experiences as a nurse working in the Australian aged care industry and currently as a gerontologist and the principal consultant within the Frontline Care Solutions group of companies. This entity designs and delivers contextualised learning and development for the care sector in Australia and New Zealand.

Historically in Australia the residential aged care or geriatric care model was heavily grounded in mental health work ethics and used the term psychogeriatric nursing to describe the platform of delivery. This contributed to the establishment of a strong mental health nursing workforce, with many nurses who worked in the aged care sector having specialised mental health qualifications, coupled with a strong preference for working in this industry. As a result the care of the frail and elderly was often based on an institutionalised model of care and lacking in a person-centered approach.

Typically the registered nurse role in the care of the elderly was one that reflected practical application of the fundamentals of nursing, providing predominately direct clinical interventions such as medication administration and general nursing care on a day-to-day basis. Nurses worked with transitioning the patient into a palliative stage and eventually the end of life, without the assistance of what is now termed a 'Care worker' or 'Nursing Assistant'. Registered nurses took directives from the medical team, and generally the work was considered heavy but not technically challenging. However, the push for international reform in elder care has witnessed many changes in the way society sees and values the care of the frail and vulnerable. Institutionalised psychogeriatric units have transformed into diverse models of residential care platforms and consumerism has forced changes in the choices offered to clients from the service provider. Culture and diversity has influenced the types of residential care services offered to the end user and in a global context the ageing population has led to an increase in consumers accessing care in a range of diverse models. 
In Australia, registered nurses found themselves entering the aged care sector as a means of transitioning into retirement from their careers in nursing, or that the evolution of nursing practice in acute care settings was changing rapidly and required a higher application of skill from the nurse. The introduction of the Bachelor of Nursing qualifications saw an increasing number of older nurses making the transition from acute settings to geriatric care, since in previous decades the nursing environment was conducive to hospital-based practices and the fundamentals of nursing care. The introduction of the nursing assistant saw the registered 'nurses' role' change from direct nursing care to becoming more specific in clinical governance, medication administration and team leadership or management.

The role of the registered nurse in aged care today is both complex and diverse. As a result of the increasing numbers of elderly entering residential care and the reduction in the number of registered nurses entering this sector of healthcare, registered nurses are responsible for the clinical governance of large numbers of elderly clients through the management of multidisciplinary health teams. Nurses are educated through a culture of direct nursing process, and in general they are not educated in the management skills needed for clinical governance and supervision of other -health-related services staff. The registered nurses in residential aged care today finds themselves less 'hands on' in direct care activities and more focused as team leaders responsible for delegating care management of many elderly people and the services that are provided to them.

\section{Structure of this Thesis}

The thesis comprises seven chapters. Chapter 1 presents the introduction to the study and its objective. The background to the study is presented in Chapter 2.

Chapter 3 includes the secondary analysis of the international evidence following the conventions associated with the systematic review process adhered to by the Joanna Briggs Institute. Chapter 4 presents search results and main findings. Chapters 5 and 6 describe the synthesised evidence generated from the analysis. Also included chapters 6 are the discussions of each theme and synthesis and what all these syntheses contribute in terms of appropriate support. Chapter 7 summarises the study and, based on the synthesis, suggests areas for future research. 


\section{Chapter Two: Background to the Study}

This chapter has been written to provide an understanding to the background of the study. The many changes and reforms in aged care over the past 2 decades have seen a significant increase in skills training to the role of the registered nurse within residential aged care models. With numerous changes to service models and nursing roles this has lead to a rise in discourse within the industry as the registered nurse is identified as a leader of the care team. Nurses are traditionally taught to nurse and care for the frail and vulnerable, however today they require taught skills in clinical leadership and management.

The role of the registered nurse $(R N)$ in the residential aged care facility (RACF) is as complex as it is diverse, as nurses attempt to manage the individual impact of ageing and the expectations of clients and their representatives in regard to care needs. ${ }^{1}$ Nurses are required to provide leadership and guidance in care directives, provide learning and development to subordinate staff and team members as well as assisting clients to make informed decisions, particularly on issues about treatment choices, palliative pathways and end of life issues. ${ }^{2,3}$ Concerns are growing over the increasing numbers of nurses leaving the aged care sector. ${ }^{1,4} \mathrm{~A}$ review of the literature identified that $\mathrm{RNs}$ are considered to be the clinical leaders in aged care and that leadership is the hallmark of effective management and retention within the service. However, recruitment to this healthcare sector is low. ${ }^{4}$ Numerous worldwide studies have identified the devalued image of working with elderly people, and this is further evident in the limited focus on geriatric nursing in the undergraduate nursing curricular. ${ }^{5}$ This represents challenges to the age care industry in order to attract and retain nursing staff, but also creates a barrier for nurses wanting to acquire advanced skills in geriatric nursing practice.

The literature demonstrates that the aged care, long-term care (LTC) and geriatric care environments are characterised by turbulence, complexity and rising frustration as a global increase in the older population puts pressure on the healthcare system to provide choice in services. 2 . 6 Hence leadership issues have increasingly caught the attention of researchers during the past few decades. ${ }^{7,} 8$ Organisations are now funding studies in order to develop strategies to ensure survival of the industry within diverse and changing workplace environments. ${ }^{6}$ 
A number of systematic reviews and literature reviews have investigated the impact of leadership and management on staff experience in the healthcare services sector, ${ }^{2,9}$ as well as in the aged care context. ${ }^{7}{ }^{10}$ These experiences have included staff turn-over patterns, staff members' decision to leave or continue working in this care environment, and the impact of workforce movements on quality of resident care. Moiden ${ }^{6}$ claims that leadership is generally acknowledged as being context-specific, which in itself provides challenges to residential care homes as they are heavily bureaucratic and over-regulated. Leadership within the residential aged care will depend on the leadership style of the individual in charge at specific times.

As an example, Pearson and colleagues $(2007)^{11}$ synthesised the best available evidence in relation to nurse leaders, leadership styles, the experiences and perceptions of their management and leadership role in the acute healthcare environment. This comprehensive systematic review identified the positive impact of effective leadership and management on staff productivity and care quality. However, the evidence generated from this review related to the general healthcare environment focusing on wider leadership issues with no specific focus on the residential models of aged care. ${ }^{11}$ Aberdeen and Angus $(2005)^{2}$ identified that the leadership of the Chief Executive Officer (CEO) within general healthcare environments can be heavily influenced by the collective power of the medical professionals within the team and their focus on quality outcomes for the individual. In the case of residential aged care, this collective group is underrepresented in management roles, and clinicians hold little if any managerial skills. This renders them subservient to the regulations and compliance expectations of the organisation. Clinicians who have managerial roles in residential aged care facilities quickly lose their skills of their original professional skills base as a nurse. ${ }^{2}$

Building on the work of Pearson et al. (2007) ${ }^{11}$, another systematic review by Jeon and colleagues $^{10}$, investigated the relationship between leadership, management, staff retention and turnover in the complex residential aged care setting as well as the costs, benefits and impacts of an effective workforce. The review identified five themes associated with the impact of leadership and management, namely: (i) staff job satisfaction and retention; ii) successful change and positive work place culture; (iii) staff productivity and unit performance; (iv) care quality and resident outcomes; and (v) associated costs. ${ }^{(10)}$ 
However, much less is known about the systems and policies required to facilitate effective leadership and management in aged care. . On this theme, these reviews could not articulate in-depth information or document the synthesised evidence on personal meaning of a particular leadership and management role of the RN in this complex area of aged care, and related more to nurses' experience in general healthcare environments.

A paper written by Anderson (cited in Jeon et al. 2010) ${ }^{10}$ identified in the findings of their narrative synthesis, that the leadership role of the nurse manager has become an emerging key driver in a healthy workforce culture. However, in the past 10 years there has been a significant decline in nurses being retained as managers in residential aged care while the role of the nurse in management and leadership has grown extensively in relation to its responsibilities. Many RNs are poorly equipped with managerial leadership skills and find themselves unprepared for the complex supervisory role they hold in aged care. This reflects their training and role description within the organisation. ${ }^{10} \mathrm{~A}$ study conducted by Fussell et al. ${ }^{4}$ investigated the experiences of newly graduated nurses from the Bachelor of Nursing programs entering the residential aged care sector in Australia, and recommended that a clear definition for the role of the registered nurse in aged care should be standardised into the degree programs in order to increase or improve the retention rate of nurses in this area.

A critical review of issues surrounding nursing education and training in aged care, and the current nursing shortages faced in the Australian aged care sector, is presented in the review prepared by Pearson and colleagues in their 2001 systematic review. ${ }^{8}$ On the basis of observational and descriptive studies addressing the issues in residential and community-based aged care, both in Australia and overseas, this review examined and recognised the best available information on concerns surrounding training and education for nurses who were either studying to work in, or were currently working in aged care. However, this review did not focus on the RN as a leader in the aged care sector or the experiences of nurses in their roles. The authors indicated further research is needed in leadership styles, learning and development for nurses in general, particularly in the aged care sector. ${ }^{8}$

Nurse retention and leadership is a contentious topic within the healthcare sector, with ample examples of the relationship between nursing turnover, retention, nurse 
leadership, the autonomous role of nurses and the satisfaction of the patient. ${ }^{12}$ Chenoweth et al. (2010) ${ }^{13}$ conducted a systematic review on the retention and recruitment of nurses into aged care in order to identify the best strategy for this crisis. The review described the culture and experiences of the nurses in the working environment that identified an area in need of improvement in organisational recruitment and retention. New policy frameworks had to be developed to reflect the same caring and nurturing values that nurses hold strongly. This review demonstrates a focus on the positive aspect of the specialty care area that is required to provide support and structure to improve retention and recruitment rates, however did not elaborate on the experiences of the nurses being asked to clinically lead teams in daily care.

Research into the experiences of newly graduated registered nurses identified the confusion experienced by the RN when confronted with different levels of expectation in the roles from key stakeholders and other staff ${ }^{4}$ Registered nurses expressed their lack of preparation for the role and found themselves either taking on too much responsibility outside their skill level, or feeling restrained in their role. Dumas et al. (2009) ${ }^{14}$ described the current need for organisations to provide professional nursing entry points for unregulated care workers to be formally trained in specific geriatric nursing roles, as these staff already have the underpinning culture and positive attitude towards the industry. ${ }^{14}$ Career pathways need to be developed to improve retention of qualified workers already in the system before they leave due to frustration. A study of New Zealand nurses ${ }^{15}$ expresses a strong sense of isolation and frustration being experienced by the registered nurse because there is limited career development and almost no structured education pathway to improve on the skills needed to fulfill the complexity of their role.

While a number of systematic reviews have been carried out that contextualise the findings in leadership requirements and industry expectations for health and aged care in general, they do not focus on the experience of the professional nurse who works in that role and performs in the key performance areas. Hence to-date no systematic review has been published on this specific topic. 


\section{Factors contributing to the global shortage of nursing professionals}

The extant literature is filled with discussion on the factors that contribute to the global shortage of nursing professionals in general. Research initiated by the International Council of Nurses (ICN) in collaboration with the World Health Organization (WHO) identified five themes of significance contributing to the factors influencing nursing shortages have been identified, including : 1. Policy and practice improvement. 2. Economic funding to address the crisis. 3 . Retention and recruitment including the migration of nurses. 4. Leadership in nursing, and 5. Workforce planning. ${ }^{16}$ The push and pull factors associated with the immigration of qualified nurses is problematic to the balance of professional nurses in countries such as Ghana and the Philippines. ${ }^{16}$ The experienced shortage is because of the migration of nurses to developing countries where the pay and conditions are an improvement on their current lifestyle. Migrating nurses throughout the European Union are filling the void created by nurses who are in a position to meet the migration criteria to more developed countries such as Australia and the USA. Notwithstanding this the shortage of nurses has been at a global crisis point since $2002 .^{16}$

A study in the USA ${ }^{17}$ reinforced the findings of the ICN and WHO in that it discussed the contributing factors to the nursing shortage in the country as being: 1 . The migration of nurses globally. 2. The poor image of nursing. 3. The changing work environment of nursing. 4. The ageing RN population, and 5. The reduced numbers of new intakes to the profession. ${ }^{16,17}$ As the number of nurses who graduate from degree qualifications falls, the need for nurses in aged care settings is increasing. Nurses as a collective group are not paid at a rate that is considered to be on a par to other healthcare professionals or qualified occupations such as teachers and lawyers.

\section{Factors contributing to the global shortage of nursing professionals in aged care}

Population ageing is a global phenomenon that has reached a dangerous point in some countries and the experience of a health epidemic is exacerbated by the increased number of nurses needed to deliver care. The registered nurse in the aged care environment is traditionally from an older demographic, reaching the end of their career and leaving the profession with a shortage of replacement nurses. ${ }^{18}$ There is enough evidence to conclude that reforms in aged care have been a significant contributor to the numbers of nurses leaving the profession from the aged care sector. ${ }^{19}$ There is a strong 
correlation between the changing work environments and roles of registered nurses in aged care practice as nurses struggle with the tensions being experienced that are influenced by dealing with change, conflicts in care and over-regulation.

Nurses as a subculture in aged care are not experiencing the same parity in pay and conditions as other nurses being recruited in general care or acute care settings. ${ }^{20}$ In practice many registered nurses see their role requiring many skills that cross over boundaries in care to include skills and understanding of other professions. The education and training for specialised skill sets is often unsupported by the organisation and once gained by the nurse at their own cost, it is used as a career development strategy to leave geriatric care and work in a setting that offers better wages and conditions. The International Council of Nurses has indicated the changing work environments of aged care nurses require macroeconomic funding to improve the specialised role and image of nurses in this field of care as its needs increase with ageing populations.

The experiences of newly graduated nurses that complete the practical placement of their studies in an aged care environment have illuminated common themes addressing the reluctance of graduates to enter aged care as a career. ${ }^{4}$ These themes include the nurses holding an ageist attitude towards their elderly clients, the perceived lack of status granted to an aged care or geriatric nurse, the poor image of nursing in this field, and the acknowledged lack of excitement associated with non-acute or non-critical care nursing environments. ${ }^{4}$ Much of this cultural interpretation is developed through the learning pathways in degree level studies as nursing students experience different workplace settings and interact with other nurses to build on their own direction. Review of the literature demonstrates that senior management in aged care services does not offer enough support, particularly for improving the role of the nurse, and this is reflective in the large amount of discourses being published in opinion papers and presented at nursing conferences. 


\section{The introduction of healthcare workers}

The International Year of the Older Person in 1997 witnessed greater emphasis on developing and delivering reform in the provision of healthcare given to the frail and elderly. Since global reforms in aged care were implemented, specifically in Western economies, there has been a significant change to the residential models of long-term care. Critical to the concept of change has been the introduction of allied healthcare teams and in particular the development of assistants in nursing (AIN) and the healthcare worker. The assistant in nursing (AIN) is experienced differently internationally in terms of how they are employed. The United States of America and the European Union have developed a pathway of education and registration of such workers at a division of nursing practice that holds a scope of practice and a standard of competency. Countries such as Australia and New Zealand have implemented the roles; however, they have not yet incorporated the scope of practice into the regulated nursing profession.

Notwithstanding this, the role of the registered nurse has evolved from a position of 'doing' nursing care to a role of delegating tasks to the subordinate assistants. These changes in care delivery have seen the key performance areas for organisations also change to models of care that require one registered nurse leader to maintain large-scale governance of clinical care to many clients. They do this by utilising the skills of care workers to deliver the services and implementing multidisciplinary healthcare team approaches. Much of the literature demonstrates the confusion for registered nurses in understanding role responsibilities and scopes of practice between varying team members, and a lack of confidence in delegation and accountability. Nurses express their feelings of isolation in decision-making and a lack of professional respect from care staff. Nurses also feel that their perceived image as a specialised nurse is being steadily replaced by the responsibility of management and regulation according to organisational requirements.

\section{Discussion}

The qualitative studies included in this systematic review have presented a broad and global range of experiences in aged care and geriatrics in the residential setting. The papers suggest a diverse range of role interpretation for nurses working in residential care 
settings and models of care being used for the care of the elderly. Despite these papers investigating the working conditions in different countries, there is a consistency in the findings suitable for meta synthesis.

While the participants' experiences seemed to generate an abundance of negative themes, the positive experiences were also well established. Nurses in the residential care setting for the elderly have a strong motivation to work in aged care. ${ }^{21-23}$ Descriptions of positive attitudes towards education programs and professional improvement are commonly referred to across the papers. Nurses experienced feelings of being valued at different times by different people in their practice. ${ }^{20}$

Organisational expectations have a major impact on the experiences of nurses in leadership roles. Capezuti et al. $(2007)^{21}$ and Hasson et al. (2008) ${ }^{22}$ found that the RNs who initiate clinical leadership programs for their teams are often disheartened when these programs are disrupted by staffing and time restrictions, working conditions and economic factors. The high demand on compliance and meeting accreditation standards is experienced as a problem and classed as a hindrance, creating numerous obstacles to care delivery. ${ }^{19,24,15}$

Role delineation for nurses within organisations was presented without clarity or structured boundaries. This was a finding, however, that noted and reflected the diverse working environments experienced in residential elder care. Registered nurses experience a clouding of the professional boundaries ${ }^{20}$ and nurse leadership is often shared between levels of nurses. ${ }^{20,25,26}$ This phenomenon, in conjunction with resident co-morbidities, increases the stressors that already exist in the residential care workplace. ${ }^{20,22,24,25}$ Nurses experience a sense of doubt in their competency and have little if any professional nursing support in the clinical leadership role. ${ }^{20,22,25}$ This role confusion has a negative impact on care outcomes as nurses struggle to find autonomy in their role as clinical leaders.

Juthberg and Sundin $(2010)^{25}$ highlighted the troubled conscience shared between nurses with different ranks and roles as they face ethical and professional dilemmas in care. Paradoxical feelings are experienced by nurses because they feel both valued and devalued at times in their work. ${ }^{20,25}$ Low self esteem is also experienced in that nurses feel 
their colleagues and team mates associate working in aged and geriatric care with having a poor competency in skills. ${ }^{20}$ In fact, this was reinforced on those occasions when critical clinical decision-making was needed in practice. ${ }^{21,25}$

Education has been identified in several findings and it could be categorised as being a lack of education for all staff, especially the registered nurse who is generally in charge of the clinical governance of residents in their care setting or work environment. ${ }^{15,21,22}$ Organisational barriers hindered attendance at educational or planning sessions, resources were limited and these sessions took second place to time and resources being used for matters of compliance and organisational capability needs. ${ }^{21,22}$ Staff had positive experiences when they attended education sessions and felt that more training was needed to continuously improve all levels of competency within the team. Nurses felt they would be better supported with more opportunities in education and improving practice.

Registered nurses and nurse leaders' negative experiences were balanced by the positive findings reported in Venturato (2010). ${ }^{23}$ This exploratory study was an extension of other qualitative work carried out by the author ${ }^{19}$ on the impact of a changed care model that had clear clinical leadership role delineation, training to support the registered nurses and measured outcomes regarding care. The findings of this study demonstrated the positive impact of supporting the registered nurses' clinical leadership and members of the team providing care having clear expectations about their role. The nurses shifted from 'reactive to proactive' care, and also shifted their focus from performing as individuals in a group to performing as teams and the registered nurses shifted from 'doing to leading'. ${ }^{23}$ The stress factors markedly decreased and the multidisciplinary model was well supported by the organisation. 


\section{Chapter Three: Study Design and Methods}

The following chapter describes the design and methods utilized to undertake this systematic review. The systematic review was undertaken following the specific guidelines as set out by the Joanna Briggs Institute.

\section{Review Objective}

The objective of this review was to consolidate the existing evidence in relation to the experiences of registered nurses and nurse leaders as managers and leaders in Residential Aged Care Facilities.

\section{Operational definitions}

The diversity of nursing and care settings worldwide provided both different and similar explanations of nursing roles:

For the purpose of this review, the participants and care environments were defined and characterised using terms of definition that best described the common understanding internationally.

\section{Registered Nurse (RN)}

Registered Nurse $(\mathrm{RN})$ - A nurse who holds a professional registration by a governing body, who, after completing extensive training and passing a state examination, is qualified to perform complete nursing services. ${ }^{27}$

\section{Nurse Leader}

Nurse leader - A registered nurse (as defined) who is considered a leader of nurses - a person that leads; directing, commanding, or a guiding head, as of a group or activity. ${ }^{27}$

\section{Leadership roles}

Leadership roles - Roles in the working environment that have specific Key Performance Indicators (KPIs) for leadership, delegation and accountability of and for junior staff and peer groups. ${ }^{27}$ 


\section{Management roles}

Management roles - Roles in the care working environment that have specific KPIs for the management of resources, staff, organisational capability, policy and procedure and including performance management. The act, art or manner of managing, or handling, controlling, directing, etc. ${ }^{27}$

\section{Residential aged care facility (RACF)}

Residential aged care facility - A facility that provides care service and assisted living to older people residing in it (i.e. aged care home; nursing home; nursing home for the aged; hostel for the aged; residential aged care home). ${ }^{27}$ It includes the following:

- Long-term residential care home

- Community homes

- Shared care house

\section{Inclusion criteria}

\section{Type of participants}

This review considered all publications that included registered nurses (RN) and nurse leaders working in residential aged care facilities (RACFs) and residential service models that are specific to care for the elderly.

\section{Phenomena of interest}

The phenomena of interest for this review is the personal meaning of a particular leadership role as experienced by the RNs and nurse leaders in any type of residential aged care settings

\section{Type of studies}

This review considered any qualitative studies investigating the experiences of nurse leaders involved in clinical leadership and proactive care management in RACF settings, including, but not limited to phenomenology, grounded theory, ethnography and feminist theory. 


\section{Exclusion criteria}

This review excluded papers that involved:

- Quantitative studies

- Text policy papers

- Studies conducted beyond the aged care and long-term care sector

- Studies not published in English

- Studies that were not published between January 1997 and February 2011

\section{Search strategy}

The literature search was designed to identify any studies published in English between 1997 and 2010. The start date of 1997 was selected because that was the International Year of the Older Person, which was pivotal in the emergence of national and international reforms in aged care Unpublished studies and hand searches of relevant journals were also included as part of the search. A three-stage search strategy was undertaken in this review. An initial limited search was conducted in MEDLINE and CINAHL databases to identify the key words contained in the title or abstract and index terms used to describe the relevant terms in the article. A second extensive search was undertaken and extended to other relevant databases using all identified keywords and index terms. The third step involved searching reference lists and bibliographies of included articles for additional studies.

The titles and abstracts identified from the search were assessed independently by two reviewers according to the inclusion criteria. Full texts were retrieved for all studies meeting the inclusion criteria. If the title and abstracts were inconclusive, full texts were retrieved and thoroughly evaluated against the inclusion criteria. Once the papers were retrieved, studies were again assessed for applicability to the inclusion criteria in order to determine their relevance to the review objectives.

The search strategy used was as follows: 


\section{Databases}

- PUB MED

- MEDLINE

- CINAHL

- Scopus, and sub databases

- PsycINFO

- Google Scholar

- Dissertation Abstracts International

- Australian Digital Thesis Program

- Mednar

\section{Unpublished studies or Grey Literature}

Globally, the voice of nursing in relation to aged care health care work is largely represented through opinion papers and industry conferences. Most of the extant literature is not peer reviewed and many studies were examined to be incomplete. Because of the large amount of grey literature that was identified in an initial search, it was decided not to include grey literature in the research of this comprehensive systematic review. This thesis has acknowledged some articles that were found to provide underpinning knowledge of the discourse being presented globally.

\section{International and Australian Government bodies or association web sites}

- Department of Health and Ageing Australia

- Royal Australian College of Nursing

- International Council of Nursing

- The World Health Organisation

\section{Assessment of methodological quality}

Qualitative papers selected for retrieval were assessed by two independent reviewers for methodological validity prior to inclusion in the review using standardised critical appraisal instruments from the Joanna Briggs Institute Qualitative Assessment and Review Instrument JBI-QARI (appendix 2). It was planned that any disagreements arising between 
the reviewers would be resolved through discussion, or with a third reviewer. Since both reviewers were in agreement on all studies included, a third reviewer was not required.

\section{Data collection}

Qualitative data was extracted from papers included in the review using the standardised data extraction tool from the Joanna Briggs Institute Qualitative Assessment and Review Instrument JBI-QARI (Appendix 3). The data extracted did include specific details about the interventions/ phenomena of interest, populations, study methods and outcomes of significance to the review question and specific objectives.

\section{Data synthesis}

Qualitative research findings were pooled using the Qualitative Assessment and Review Instrument (JBI-QARI). This involves the aggregation or synthesis of findings to generate a set of statements representing that aggregation, by assembling the findings (Level 1 findings) rates according to their quality, and categorising these findings on the basis of similarity in meaning (Level 2 findings). These categories were then subjected to a metasynthesis in order to produce a single comprehensive set of synthesised findings (Level 3 findings) that can be used as a basis for evidence-based practice.

\section{Conflicts of interest}

There were no conflicts of interest associated with this systematic review. 


\section{Chapter Four: Results}

\section{Search Results}

Two qualitative descriptive papers ${ }^{21,22}$ described the experiences of the nurse as a clinical leader in a specific role undertaken through education to improve the outcome for care to residents in the specific clinical areas of falls management and palliative care. Both papers identified findings where nurses emerged as being highly motivated in aged care, proactive and supportive of innovation and change; they were committed to providing high quality care to residents. Other findings from these papers also highlighted the extent of organisational barriers leading to de-motivated nurses, which in turn prevented the creation of pathways for learning and continuous improvement of specific skills needed for their specialised roles. While new and diverse roles for nurses have been created by their organisation, nurses' lack of underpinning clinical knowledge and expertise concerning these new roles was evident. The authors commented that this was due to organisational barriers or problems deterring a valued structure and key performance indicator for the role.

A phenomenological study by Juthberg (2010) examined the lived experiences of the troubled conscience that nurses experienced in their work. ${ }^{25}$ The study participants consisted of two groups of nurses who deliver care in municipal community homes for the elderly in Sweden. They were selected from a previous study group, which required nurses to answer a questionnaire on stress and burnout the workplace. Invitations were sent out to three high- and three low-scoring participants from one of two groups ( $n=12$ participants). The 12 participants were offered the opportunity to participate in an interview to expand on their answers. The two groups consisted of registered nurses (RNs) and assistants in nursing (AINs) and the interviews provided the opportunity for a deeper reflection on their experiences. The findings identified their experience of paradoxical working situations and their experience of working under stress.

A descriptive qualitative study by Venturato $(2007)^{19}$ focused on 15 registered nurses in residential aged care facilities (RACFs) and was guided by a critical hermeneutic approach informed by the philosophical hermeneutics of Gadamer and the critical social theory of Habermas. The study reflected the experiences of nurse leaders during and after the 
period of political and social reform for aged care in Australia, and the implications for retention of nursing personnel.

Qualitative research designs have been used in another three papers ${ }^{4,20,24}$ using semistructured interviews to elicit descriptive and rich responses from nurse leaders in order to: firstly, understand their experiences; and secondly, relate the information to job satisfaction and nurse retention rates in elder care environments. Small groups of nurses in a number of aged care services were identified as having a troubled conscience in relation to their skills and accountability at work. The studies examined the experiences of the nurses as a result of organisational change and how their roles were structured in the context of the team.

In order to test the known literature about the experiences of nurses and clinical leadership, another paper by Venturato ${ }^{23}$ implemented an exploratory study that employed combined qualitative methods to record the experiences of registered nurses placed in a trial care model. This particular model had been designed to enhance and support clinical leadership in aged care. The study in particular demonstrated the positive influence of the lived experiences in quality care models in aged care. The study recorded the impact of creating a structured and perceived healthier workplace environment for care teams in residential aged care settings in Australia.

The key findings of each study were identified and extracted. Because of their contents, these findings could easily be placed into a set of grouped findings for this systematic review, a supportive illustration from each paper and its findings are presented in the section below:

All the eight selected studies passed the quality appraisal process and were included in this systematic review (Appendix 1). A list of the excluded studies and the reasons for exclusion are set out in Appendix 5.

\section{Main findings}

The search strategy identified discursive and opinion papers yet while they proved to be interesting in topic and content, they did not meet the requirements for inclusion in the 
review. However, some were used as background information and in the general discussion of this paper in order to place the findings of the review into a wider context. ${ }^{13}$ It was interesting to note that there were numerous papers published prior to 1997 , which can perhaps be attributed to the intensity and focus on the need for the industry to reform during the lead-up to the International Year of the Older Person. ${ }^{6}$

A total of 107 papers were identified from the extended database search, and were retrieved for further reading and appraisal. From this search 73 papers were excluded as they were not directly related to the objective of the systematic review. A total of 34 papers were found to be applicable to the review topic, on the basis of the title and abstract. These papers were identified in the search strategy that was used for retrieving literature that met the inclusion criteria and further evaluation and methodological assessment. Of the 34 papers a total of 23 were excluded for reasons that included incongruence to the review objectives, intervention and/or outcomes. A final total of eight papers (Table 1 \& Appendix III) were included in the review. 


\section{Chapter Five: Synthesis 1 - Identifying the Categories}

Using the Joanna Briggs Institute-Qualitative Assessment and Review Instrument (QARI) tools, the findings identified during the extraction of data were analysed for common themes that led to the development of a category. These categories were then aggregated further into a synthesised finding. These categories and synthesised findings are as follows: there are 12 categories and five synthesises findings.

\section{Category 1. Motivated to work in aged care} Description:

Findings that related to the positive expressions described in findings from the included studies. .

\section{Findings contained:}

Finding 1: Staff have a strong interest in new education programs to improve and strengthen practice $(C)$

\section{Illustrations:}

1. "All facilities were highly receptive to participation in the project, and all education programs were well attended." 22 pg 5

Finding 2: Nurses in aged care hold strong values in the provision of high quality care services $(\mathrm{C})$

\section{Illustrations:}

1. "It is very rewarding in the fact that every day you can do something good for somebody...you see that you improve someone's quality of life...you hear about it in all areas of nursing but in aged care you can actually do it."19 pg 7

\section{Category 2. Registered Nurses and nursing staff feeling valued}

Description:

At times in practice the nurses reflect on feeling valued and nurses feel they experience being valued only by individuals.

Findings contained: 34,43 , and 44

Finding 34: Positive education and support from the $R N$ to the $A N$ is vital $(C)$ Illustrations: 
1. "if it wasn't for the education we get I wouldn't do the role.....the $R N$ is right behind you if something goes wrong she's there."23 pg 167

\section{Category 3. Not enough professional education for the $\mathrm{RN}$ to remain confident Description:}

Nurses feel that there is not enough opportunity and too many barriers in updating their professional education to create better practice.

Findings contained: 3 and 26

Finding 3: The RNs feel inadequate about decision-making and competency (C) Illustrations:

1. ....and you feel insufficient.... when you only offer a significant dose (to the resident in pain)... why didn't I put my foot down earlier? 25 pg 24

2. Not being on top form and realising what the side effects would be. And then you've blamed yourself for causing constipation with our medicines//but still it was still there inside me that feeling of guilt... ${ }^{25 \mathrm{pg}} 24$

3. ...then I also get a bad conscience... many things in elderly care is about being one step ahead, to plan everything....you have to manage...(the day). ${ }^{25} \mathrm{pg} 24$

Finding 11: The specialised role of the link nurse is needed to improve the education and skills of the nursing staff to provide better care (C)

Illustrations:

1. Prior to training there was a significant amount of isolation, in a nursing home, you just rely on your own skills. ${ }^{22 \mathrm{pg} 238}$

Finding 26: A lack of clinical skills and education for RNs (C)

Illustrations:

1. I have worked here for 12 years and have had no paid professional development time. ${ }^{15} \mathrm{pg} 13$

Category 4. Organisational barriers interfere with the quality of care to individuals, service provision and staff support

Description:

Findings that refer to organisational impacts in the daily environment. The nurses' experience of the management and the impact it has on their daily lives. 
Findings contained: $7,8,13,17,18,19,20,21,22$, and 23

Finding 7: RNs feel that quality in care refers only to compliance and accreditation (C) Illustrations:

1. ...they (accreditors) break the spirit of the home a lot of the time $24 \mathrm{pg} 186$

Finding 8: RNs have a low sense of job satisfaction and experience poor staffing levels (C)

\section{Illustrations:}

1. I am just surviving on a day to day basis.... the pay rate and conditions at work are difficult..... we can't attract care workers from the local city. ${ }^{15 \mathrm{pg}} 14$

Finding 13: Too much documentation (C)

Illustrations:

1. We complain about the paperwork all the time...but we do it. ${ }^{24} \mathrm{pg} 187$

Finding 17: Reform and change has increased workloads and decreased time with residents $(\mathrm{C})$

\section{Illustrations:}

1. It seems strange that reform was meant to improve things for them and now we don't get time for them. ${ }^{19} \mathrm{pg} 9$

Finding 18: Overworked and understaffed (C)

Illustrations:

1. Sometimes you just feel overwhelmed. ${ }^{24} \mathrm{pg} 187$

Finding 19: Organisational barriers or problems impacted on attendance rates at training and disheartened the facilitator $(\mathrm{C})$

Illustrations:

1. It ended up we began with eight and ended up with two at our last session, which is disheartening when you organise the session and don't get the interest. ${ }^{22} \mathrm{pg} 239$

Finding 20: Nurses feel that the quality in care is for the regulation and accreditation aspect $(\mathrm{C})$ 


\section{Illustrations:}

1. Now when we talk of quality it's really the quality of the system. ${ }^{19} \mathrm{pg} 9$

Finding 21: Nurses feel hindered by pre-determined conditions and organisational demands $(\mathrm{C})$

Illustrations:

1. ...you try in some way to gain time $25 \mathrm{pg} 24$

Finding 22: There is a lack of funding for project implementation (C)

Illustrations:

1. A lack of reimbursement for rehabilitative services, staff were not funded for attendance in the project. ${ }^{21} \mathrm{pg} 7$

Finding 23: Increased workloads and compliance interfered with resident care (C) Illustrations:

1. You leave feeling like you have only done half the job. ${ }^{19} \mathrm{pg} 9$

Finding 24: High administrative turnovers (C)

Illustrations:

1. Facilities experience a high turnover of managers and senior administrators that result in projects and roles being hindered and changed ${ }^{21}$ pg 7

\section{Category 5. A lack of professional nursing support}

\section{Description:}

Nurses feel that they experience a lack of professional support from colleagues and specialist services in care planning and decision-making.

Findings contained: 9 and 14

Finding 9: RNs experience a lack of timely intervention from the GP (C)

Illustrations: 
1. I called the GP early in the morning to say that she had been in pain all night and we had nothing prescribed. He came at 7pm that night by which time the pharmacy had closed. An RN (who was not on duty) drove 2 hours to a pharmacy so the resident did not have another night in pain. ${ }^{15} \mathrm{pg} 15$

2. The GP puts our residents last and we feel demeaned by their lack of interest. ${ }^{15} \mathrm{pg}$ 15

3. Yes! I answered all the time, that I would try and get a hold of a physician....because of course I couldn't say to the resident that I don't have a doctor that is responsible for you....there isn't anyone who wants to be responsible for your care. ${ }^{25 \mathrm{pg} 23}$

Finding 14: RNs feel frustrated because they are asked to carry out duties that cross over between nursing, social care and administration (C)

\section{Illustrations:}

1. You are like a spider in a cobweb.... and try to be obliging and to be on time, trying to coordinate every little thing possible. ${ }^{20 \mathrm{pg}} 269$

\section{Category 6. Feeling disempowered and inadequate}

\section{Description:}

RNs and nurses often feel disempowered and inadequate during their practice.

Findings contained: 27 and 36

Finding 27: Inability to implement individualised care planning (C)

\section{Illustrations:}

1. Staff were not equipped with the skills to carry out assessment or care planning and it was too overwhelming for one $R N .^{21} \mathrm{pg} 7$

Finding 36: RNs internalised feelings of negative professional beliefs $(C)$

Illustrations:

1. ....unable to return to acute setting as they have lost their skills. ${ }^{19} \mathrm{pg} 8$

\section{Category 7. The industry does not respect the workforce}

\section{Description:}


RNs and nurses experience poor recognition from colleagues and that aged care is reflective of poor clinical expectations and working conditions.

Findings contained: 4 and 6

Finding 4: Being a lonely and invisible fixer of problems at work (C)

Illustrations:

1. I don't think the hospital nurses understand they just hand in a report and go home; but here you have to fix everything. $20 \mathrm{pg} 270$

Finding 6: RNs feel disempowered and inadequate due to the lack of collaboration with others in the multidisciplinary care team $(C)$

Illustrations:

1. I have a case in mind...it was a pressure ulcer on a leg that the AN's didn't report to me. $25 \mathrm{pg} 23$

2. They could have reported me, it didn't matter. It felt like...I rather make a formal error...to give without prescription...than letting the patient suffer. ${ }^{25 \mathrm{pg} 23}$

\section{Category 8. Geriatric nursing is a specialised field that warrants its own} professional identity

\section{Description:}

RNs and nurses feel that the skills needed for geriatric nurses are specialised and this gerontology practice warrants its own significant identity as a profession.

Findings contained: 10 and 13

Finding 10: RNs feel there is a lack of professional nursing support (C)

\section{Illustrations:}

1. Minimal RN staffing levels meant minimal if any opportunity to provide supervision and support to a new graduate, and placements were reported to be rarely if at all offered to post graduates. ${ }^{15} \mathrm{pg} 13$

2. RNs felt they got support when needed but need more, gave support most of the time, and unaware of support available. ${ }^{15} \mathrm{pg} 13$

\section{Category 9. Providing leadership opportunity improves practice}

\section{Description:}


When provided with positive working leadership roles and training, the experience was also positive in helping improve practice.

Findings contained: $31,32,33,34,35,38$, and 39

Finding 30: Nurses express value for their practice (C)

Illustrations:

1. It's rewarding that every day you get to do something special for somebody ....they don't want to know unless something bad happens. ${ }^{19} \mathrm{pg} 7$

2. I'm sort of on the outside and can look in from a different perspective; it feels liberating. ${ }^{20 \mathrm{pg}} 268$

Finding 31: RNs experience an increase in job satisfaction with positive models of care when they move from reactive to proactive care $(C)$

Illustrations:

1. We're trying to get more involved in clinical indicators and documenting that, and trying to get an overall picture instead of just focusing on clinical review. ${ }^{23}$ pg 168

Finding 32: Experience a need for positive management support (C)

Illustrations:

1. The lack of recognition for the role and the need to free up staff from clinical areas all had impact on delivery. ${ }^{22} \mathrm{pg} 240$

Finding 33: Proactive approaches decrease the stress and provide positive experiences (C)

Illustrations:

1. it's heaps of work....and the RN manager allocation of time for me offline was vital. $^{19)}$ pg 8

Finding 34: Positive education and support from the $R N$ to the $A N$ is vital $(C)$ Illustrations:

1. if it wasn't for the education we get I wouldn't do the role.....the RN is right behind you if something goes wrong she's there. ${ }^{23} \mathrm{pg} 167$

Finding 35: RNs experience the shift from 'doing' to 'leading 'in a positive care model (C) Illustrations:

1. it's freed up the nurses to lead and make less mistakes ${ }^{23} \mathrm{pg} 166$ 
Finding 38: RNs experience having the ability to build trust and provide support (C)

\section{Illustrations:}

1. ...NA's [sic] have a need to feel secure when they are caring for severely ill people. $^{20 \mathrm{pg}} 268$

Finding 39: Nurses have a valued feeling but also devalued feeling towards practice (C) Illustrations:

1. It's rewarding that every day you get to do something special for somebody'....they don't want to know unless something bad happens. ${ }^{19} \mathrm{pg} 7$

\section{Category 10. RNs feel they are not up to standard and worry about accountability}

\section{Description:}

RNs reflect on skills and competency when making decisions and dealing with organisational barriers in aged care.

\section{Findings contained: 37}

Finding 37: RNs were stressed about issues of accountability (C)

\section{Illustrations:}

1. I have significant issues over the accountability of some care staff....But I do not hire them ...nor can I fire them. ${ }^{15} \mathrm{pg}$

\section{Category 11. Nurses feel that aged care work is reflective of having a poor competency}

Description:

RNs feel that working in the aged care sector reflects poor competency according to their colleagues, and the industry attracts poor quality and untrained staff.

Findings contained:

Finding 15: RNs feel exhausted due to the increase in co-morbidity and lack of time to deliver care (C)

\section{Illustrations:}

1. It's so demanding, I get so tired, I should retire at 61 in fear of making mistakes. ${ }^{20} \mathrm{pg}$ 269

Finding 16: RNs feel that aged care work is reflective of poor competency (C) 


\section{Illustrations:}

1. They are starting to get resentful and angry. It's a bit of a backlash against the notion that if you can't cut it in acute care than you go to aged care...like it's a copout... $^{19}$ pg 8

\section{Category 12. Care -related stressors are high}

\section{Description:}

The care-related stress factors on staff and nurses in long-term care are high and their diversity ranges from organisational impact to individual residents.

\section{Findings contained: 5}

Finding 5: RNs feel belittled when hospital staff do not understand the differences in role context to RACF and they see the lack of resources and outcomes as a lack of competency $(\mathrm{C})$

\section{Illustrations:}

1. It didn't work since we didn't have the resources to monitor.....but the colleagues in hospital thought it was about a lack of competence. ${ }^{20 \mathrm{pg}} 269$

Finding 28: Care related stress is high (C)

Illustrations:

1. ...dealing with the combative resident, the one that hits you when you do your job. ${ }^{24}$ pg 186

2. If you get attached to them too much it hurts a lot when they die. ${ }^{24} \mathrm{pg} 186$

Finding 29: Many conflicts in caring that divides practice (C)

\section{Illustrations:}

1. It's like you are standing alone....the residents need your advocacy,...the staff need your advocacy....the manager tell you to do the job,.....accreditation has another expectation....you can possibly please them all. ${ }^{19} \mathrm{pg} 9$ 


\section{Chapter 6. Synthesis 2: Synthesis findings}

\section{Synthesis Finding 1. A strong motivation for aged care}

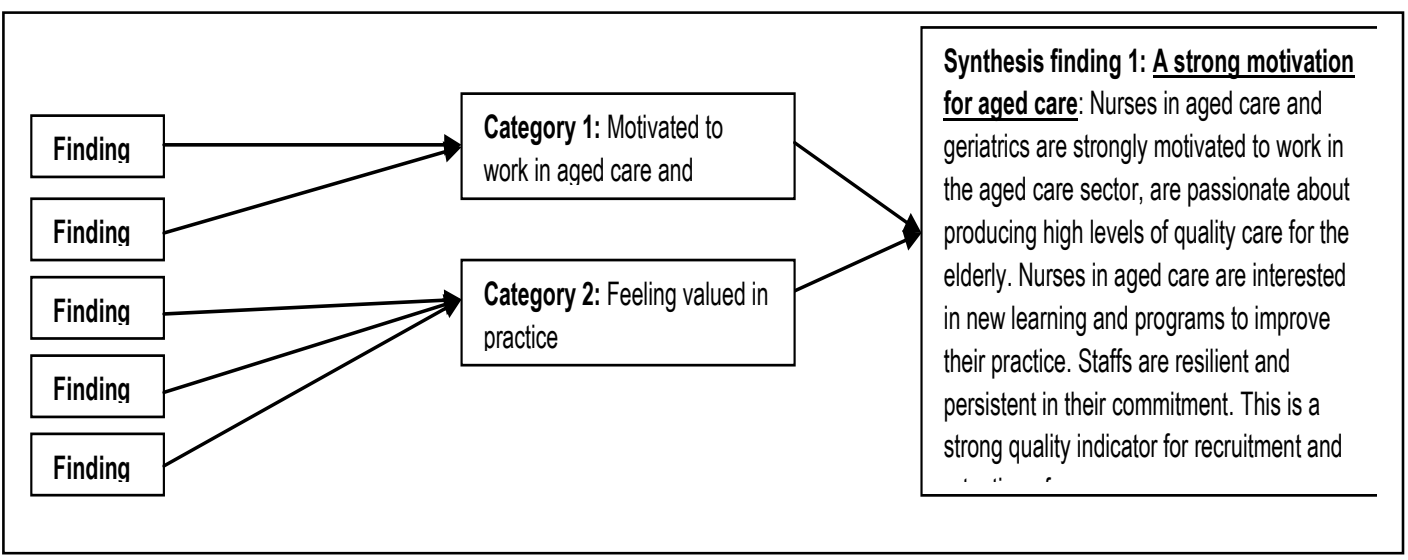

\section{Synthesis finding 1: A strong motivation to work in aged care:}

Employers and policy makers should be aware that nurses in aged care and geriatrics have a strong motivation to work in the aged care sector and like being valued by the community.

Nurses in aged care and geriatrics are strongly motivated to work in the aged care sector, and are passionate about producing high level quality care for the elderly. Nurses in aged care are interested in new learning and programs to improve their practice. Staff members are resilient and persistent in their commitment. This positive factor is important and enables organisations to identify potential leaders, structure career pathways accordingly and develop better educational courses in geriatric care management. Positive career opportunities in geriatric care are needed to improve recruitment and retain staff who possess a positive desire to work with the elderly.

\section{Synthesis Finding 2. Education in clinical leadership and management is needed}

\begin{tabular}{|l|l|l|}
\hline Finding 3 & $\begin{array}{l}\text { Category 3: Not enough professional } \\
\text { education for the RN to remain confident }\end{array}$ \\
\hline Finding 26
\end{tabular}




\section{Synthesis finding 2:}

Synthesis finding 2. Education in clinical leadership and management is needed:

Educational pathways and programs are needed to improve professional practice and promote continuous development in clinical and leadership skills.

There is a lack of educational pathways and programs for the RNs to improve their professional practice and continuous development with clinical and leadership skills. Organisations should invest in providing more focused education and pay the costs that RNs absorb when they take up study opportunities. They are already suffering low pay and conditions in this healthcare sector. Career pathways in aged care are non-existent as standards of education in gerontology do not map to specific roles in the organisations providing services. Organisations should provide education and opportunities where RNs can develop skills in clinical knowledge, communication, leadership, regulation, governance, compliance and computer literacy. Static boundaries for clinical decisionmaking should be established within organisations for clinical leaders and service managers. The RN requires training to gain confidence in: firstly, meeting organisational expectations as clinical leaders; and secondly, as healthcare team managers in order to remove emotional frustration in a paradoxical situation where feelings of inadequacy may arise. RNs often experience low self esteem and devalue their own competency when they are restricted in choice and organisational support is limited. The processes of geriatric care can lead to poor outcomes, and RNs feel that other professions criticise or question the individual skills and professional acumen of the nurse. 


\section{Synthesis Finding 3. A specialised care area that requires improved recognition}

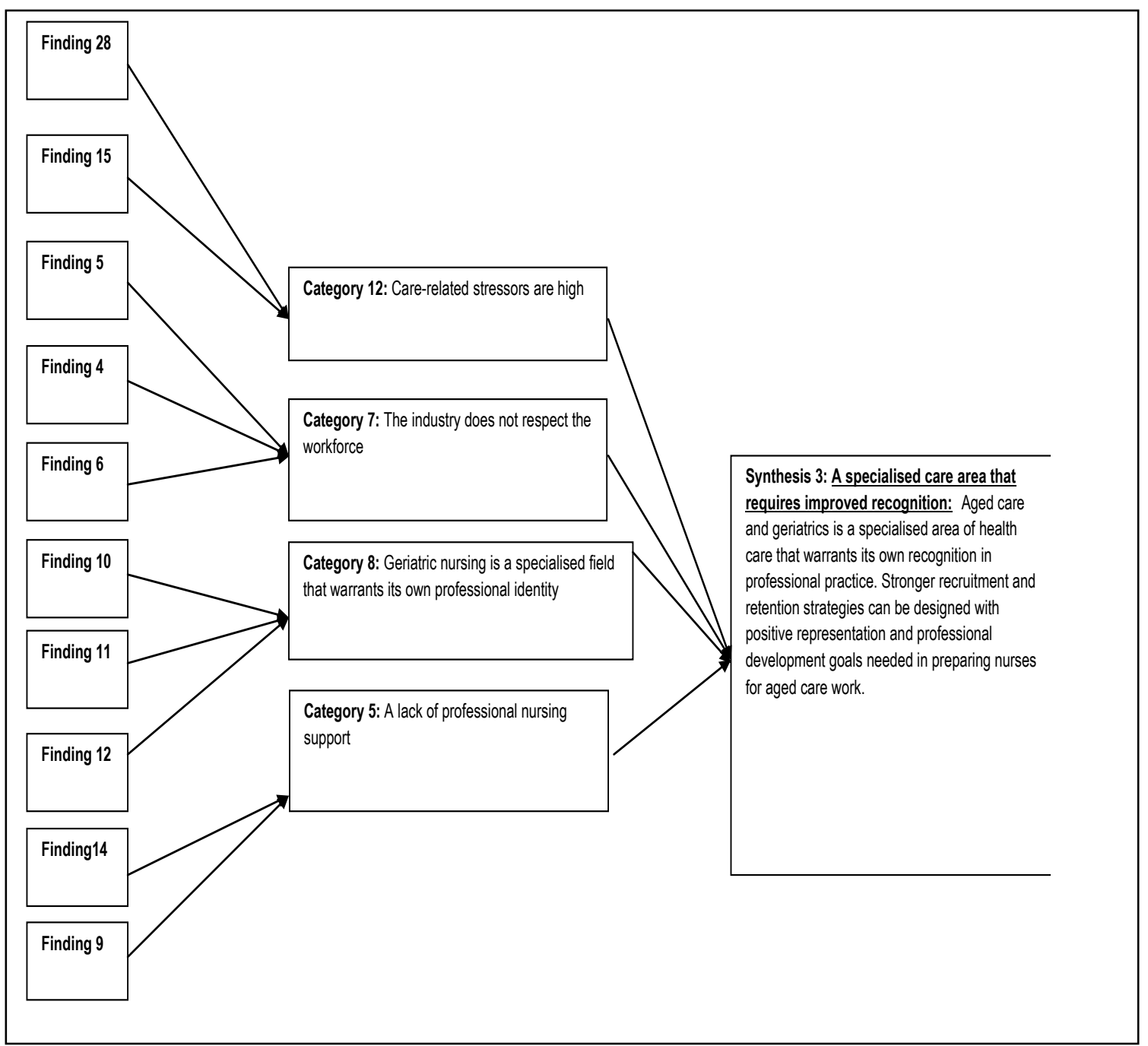

\section{Synthesis finding 3:}

A specialised care area that requires improved recognition: Aged care providers and healthcare policy makers should understand that aged care and geriatrics is a specialised area of healthcare that warrants its own recognition in professional practice.

RNs in aged care have experienced many changes to their practice that have been the subject of social and political reform in the past two decades. Aged care and geriatrics is specialised and the skills sets required include clinical leadership roles and clinical education needs for nurses, so that they can act autonomously and lead multidisciplinary teams. Greater expectations are held by the end user of services provided to elderly residents in care. Organisations need to improve clinical decision-making boundaries for nurses working in aged care to identify the level of clinical responsibility concerning regulation and compliance. Nurses, when working in isolation and away from one's 
colleagues, require critical thinking and clinical judgment and the RN must exude confidence in his/her role. RNs working in aged care and geriatrics deserve greater recognition from their colleagues in other healthcare sectors and particularly GPs. Nurses need to value the skills and autonomy that their role entails, and furthermore their pay and conditions should reflect the level and scope of responsibility they take on. Resources for structured career and learning pathways are needed.

\section{Synthesis Finding 4. Organisational barriers have a negative impact on care outcomes and continuous improvement}

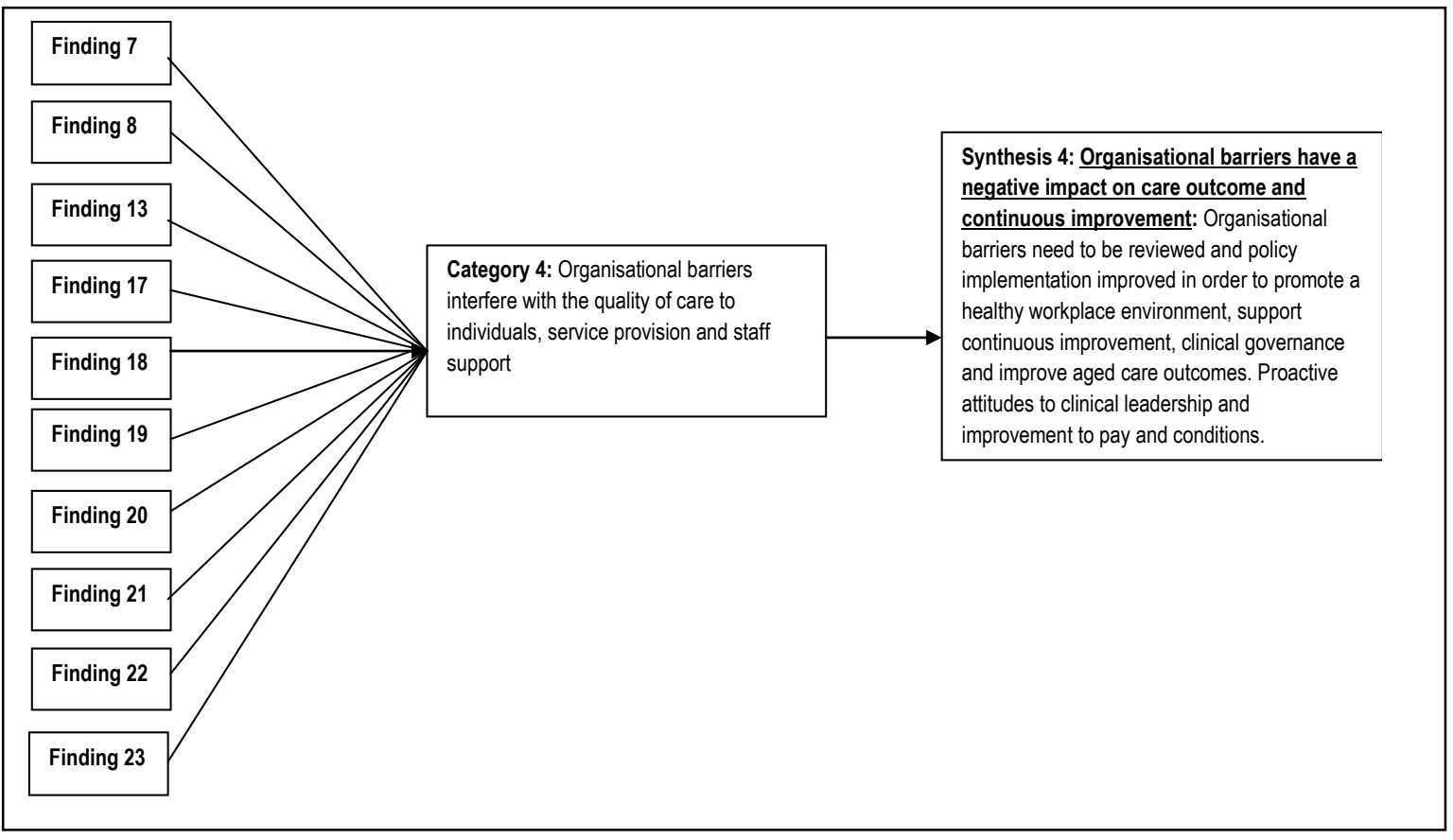

Synthesis finding 4: Organisational barriers: Organisational barriers need to be reviewed and policy implementation improved in order to promote a healthy workplace environment, support continuous improvement, clinical governance and improve aged care outcomes.

A balance between organisational requirements and best outcomes in care needs to be established. Effective leadership of the care team is best supported by senior management that values the clinical leadership role and encourages autonomy and performance management. Allocation of the organisations internal funding is required to improve models of care. Support for the RNs to develop their skills will increase their retention and that of clinical nurse leaders in healthcare. Regulation and compliance should be reviewed in collaboration with senior nurse leaders so that change can be seamlessly integrated and flexible enough so that stress decreases or is better managed. Pay and conditions in the aged care and geriatric sector need to be investigated and so 
that they are on par with other healthcare sectors. A staff-client ratio must be established to reduce staff burnout, provide safe practices and support clinical governance decisions and to ensure adequate care outcome is reached. Organisations would be well served in being proactive in reducing and simplifying the paperwork requirements.

\section{Synthesis Finding 5. Positive and proactive care models improve morale and productivity}

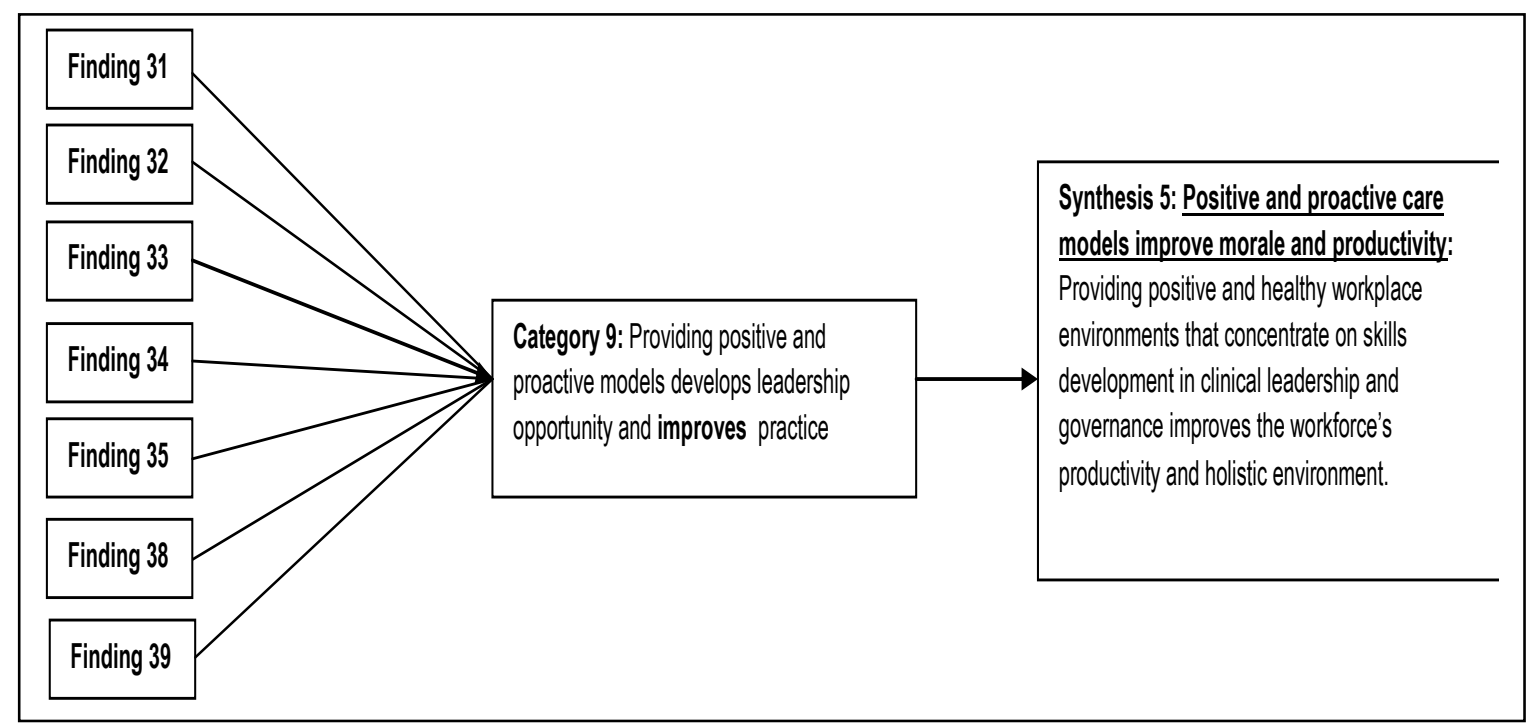

\section{Synthesis finding 5 :}

Positive opportunities of leadership changes practice: Providing positive and healthy workplace environments that concentrate on skills development in clinical leadership and governance improve the workforce's productivity and holistic environment.

RNs and their subordinate nurses who experience positive leadership training and changed or improved models of care have had a positive impact in changing practice. Nurses respond well to proactive leadership and good care modeling. Multidisciplinary health team models of care need to be investigated. The role of the Geriatric nurse Practioner (GNP) is one pathway that needs to be developed. Recognition and positive feedback for staff in geriatric care improves morale, opportunities for positive empowerment improves service delivery and care outcomes. $\mathrm{RN}$ training for aged care and geriatrics should be specialised and contextualised to so that clinical leadership and management skills are combined. Professional recognition for the diverse roles and expectations need to be aligned with remuneration. 


\section{Chapter Seven: Discussion and Conclusions}

The key findings generated in this review are generally negative in regard to the experiences of RNs and nurse leaders working in residential aged care and geriatrics. It is evident that worldwide nurses experience feelings of being devalued due to the nature of their field of practice. Organisations are seen to create numerous barriers that affect the service delivery to frail and elderly by nurses working in age care. There is an identified lack of education for professional development and role delineations and boundaries of responsibility are blurred by issues of compliance and competency to perform the duties autonomously. The care models currently being used can be improved so that the geriatric or aged care nursing profession provides structure and opportunities for career and professional development. Structured career pathways in geriatric nursing are needed to improve the professional recognition of this specialised field and improvements to work pay and conditions are required. Recruitment and retention of staff in aged care and geriatric nursing will be well supported by organisations that change to a proactive model of care delivery.

The findings of this systematic review illustrate the overwhelmingly negative experiences that RNs and nurse leaders have in residential aged care services. The organisations involved in the delivery of these care services need to examine the structure of the care models currently being used and more specifically the role of the $\mathrm{RN}$ and nurse leader. Aged care and geriatrics is a specialised field of practice that presents with complex clinical and social settings and increased stressors. Nurses require structured role delineation and guidelines on making decisions in clinical governance. Career pathways with supported education need to be designed for the nurses to enter and exit the field of practice with opportunities in management and clinical qualifications that are recognised across all healthcare sectors.

There is a strong argument for the defined role of Geriatric Nurse Practioner (GNP). The $\mathrm{RN}$ needs to reflect on their own practice with confidence and be supported in professional development and recognition in order to work towards becoming a GNP. Nurses in aged care have a resilience that proves they are strongly motivated to work in the industry, and this experience is a foundation for improved practice models that recruit and retain staff more effectively. 
The following recommendations are developed based on the meta-syntheses:

Improving the recruitment retention and capacity of nurses entering the aged care and geriatric care environment

\section{Employers and policy makers should be aware that nurses in aged care and geriatrics have a strong motivation to work in the aged care sector and want to be valued by the community.}

Aged care nursing and in particular residential aged care or nursing home work has not been considered one of the vibrant and exciting forefronts of the nursing profession. There was ample evidence throughout the extant literature globally demonstrating the personal motivation of nurses to work with the elderly. There was an underlying need to nurture which is a common characteristic in nurses who value the fundamental process of giving care to another person in their duty of care.

The diversity of healthcare allows nurses to choose an area of significance that matches their expectations in a nursing career. One of the key recommendations throughout numerous studies found during the database searching was the level of importance for identifying ways to improve the recruitment and retention of nurses in general. This systematic review has identified two key characteristics in aged care nurses: (1) they value the community expectation of quality care carried out by nurses for the frail and vulnerable, and (2) that aged care nursing meets that expectation for the nurse who wants to feel valued in for the work they do.

When nurses are looking for an area of practice that suits their personal need, aged care work attracts nurses who are motivated to do the work.

\section{Educational pathways and programs are needed to improve the professional practice and continuous development of nurses with clinical and leadership skills.}

The identified shortage of registered nursing combined with the increasing numbers of elderly entering care is a driving force for organisations to structure human resources effectively. The key performance areas of practice for the role of the registered nurse in a residential aged care model are often influenced by the organisational requirement for the 
nurse to demonstrate clinical leadership in decision making and management of care through delegation. Nurses working in leadership or management roles are challenged by the lack of their own skills training in this area.

Organisations could improve the recruitment and retention of nurses if educational pathways were established to meet any skills gaps being experienced by the RN. A systematic training needs analysis should be carried out during the recruitment and induction phase of employment in order to develop an educational pathway that reflects the needs and desires and sets goals for achievement. The individual RN could be effectively performance managed and reflect on his or her practice in order to develop personal growth and professional development.

\section{Aged care providers and healthcare policy makers should understand that aged care and geriatrics is a specialised area of healthcare that warrants its own recognition in professional practice.}

Available evidence suggests that nurses working in residential long-term care quickly identify the range of specialised skills that are necessary to meet the needs of the client and the organisation. The detailed interviews with participants in these studies have demonstrated that nurses find themselves in a paradox when they are asked to reflect on their practice. Findings express the view that nurses feel their work in long-term care of the elderly is considered by other health professionals outside the aged care sector as having low or poor levels of competency. There is a strong suggestion that the medical practioner working with nurses in these settings does not often work in collaboration with nurses as much as experienced clinicians do. This is a common phenomenon that needs to be further investigated through research in order to improve the image of professionals working in geriatric and long-term aged care.

Nurses also experience a paradox where as specialists they feel valued and respected by their clients and their loved ones in the work they do, yet they feel inadequate and incompetent when challenged by scenarios of social care needs, administration and care management. This is particularly the case when it comes to providing multidisciplinary care services to the elderly. Nurses experience the paradox where they feel valued by subordinate workers when they are confident of receiving clinical support and then are 
challenged by the diversity of team members and the skills required to manage them as teams

Organisational barriers need to be reviewed and policy implementation improved in order to promote a healthy workplace environment, support continuous improvement, clinical governance and improve care outcomes.

There is ample evidence within the findings that nurses experience many problems or barriers in providing positive outcomes in aged care that are created by an association to an organisation' policies and procedures. Nurses express their criticism of regulation within the care industry, stating regulatory compliance and accreditation standards actually interfere with and hinder the focus on positive outcomes in care.

Organisations that deliver aged care services need to re-evaluate and continuously improve quality documentation and accountability through continuous improvement of policy and operational frameworks. Recruitment and induction processes should be streamlined and focus on the personal diversity and skills mix of all staff so that the value placed on individuals within the team is enhanced. ${ }^{19,23}$ Education and training should be paramount in building and improving productivity and retention of personnel.

Providing positive and healthy workplace environments that concentrate on skills development in clinical leadership and governance improves the workforce's productivity and holistic environment.

The development of healthy workplace environments and care models that utilise multidisciplinary healthcare team management will improve the structure and delivery of services to the client base. Registered nurses are well equipped to be groomed into the role of multidisciplinary healthcare team leader, and education pathways need to be established during recruitment and induction of qualified nurses in order to create role and career structures.

Direct care workers who operate under the delegated supervision of registered nurses should have a role and duties structure reflecting the importance of their role in order to give value and meaning to their work. . Teams need to be led with good governance and proactive leadership models that are influenced and valued by the registered nurses. Registered nurses' roles should be prioritised by organisations and they also need to 
provide clear boundaries for practice. The registration of direct care workers and AINs would assist in establishing better delegation and performance management in care staff.

\section{Implications for research}

New research into the role of the RN in aged care is illustrated through the findings. Structured career pathways in aged care nursing and the established defined role of the Geriatric Nurse Practitioner (GNP) will provide positive leadership roles in aged care. Research into the management of residential elder care is implied, and the Key Performance Indicators that should be integrated into the nursing environment need further investigation. This systematic review illustrates the potential for research into establishing an audit criteria and implementation process for the skills required by the RN in aged care. As the growing need for care increases in tandem with aging populations, the implications for research can lead to clear career pathways for nurses, improved models of care and better outcomes for end users. 


\section{Appendices}

\section{Appendix 1: Flow diagram of the studies}

$F=$ papers found to match search criteria in database; $E=$ excluded papers for reason; $R=$ papers retrieved for qualitative appraisal; $I=$ papers included in the critical appraisal

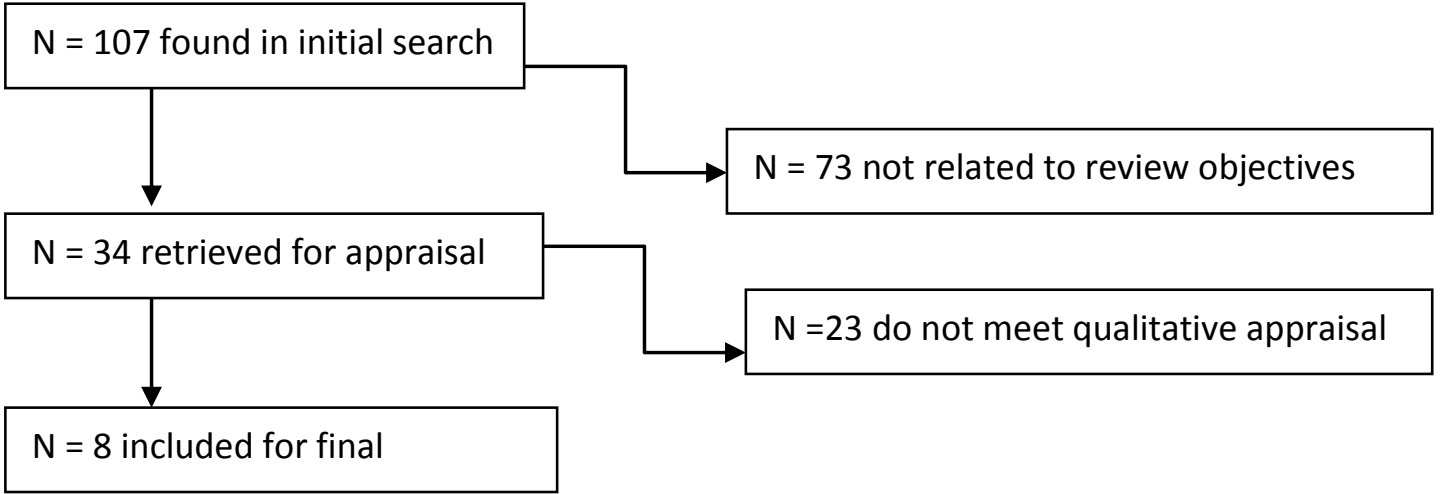

\section{Appendix 2: QARI Appraisal instrument}

\section{Criteria}

1) There is congruity between the stated philosophical perspective and the research methodology.

2) There is congruity between the research methodology and the research question or objectives.

3) There is congruity between the research methodology and the methods used to collect data.

4) There is congruity between the research methodology and the representation and analysis of data.

5) There is congruity between the research methodology and the interpretation of results.

6) There is a statement locating the researcher culturally or theoretically.

7) The influence of the researcher on the research, and vice-versa, is addressed.

8) Participants, and their voices, are adequately represented.

9) The research is ethical according to current criteria or, for recent studies, there is evidence of ethical approval by an appropriate

body.

10) Conclusions drawn in the research report do appear to flow from the analysis, or interpretation, of the data. 


\section{Appendix 2: QARI data extraction instrument}

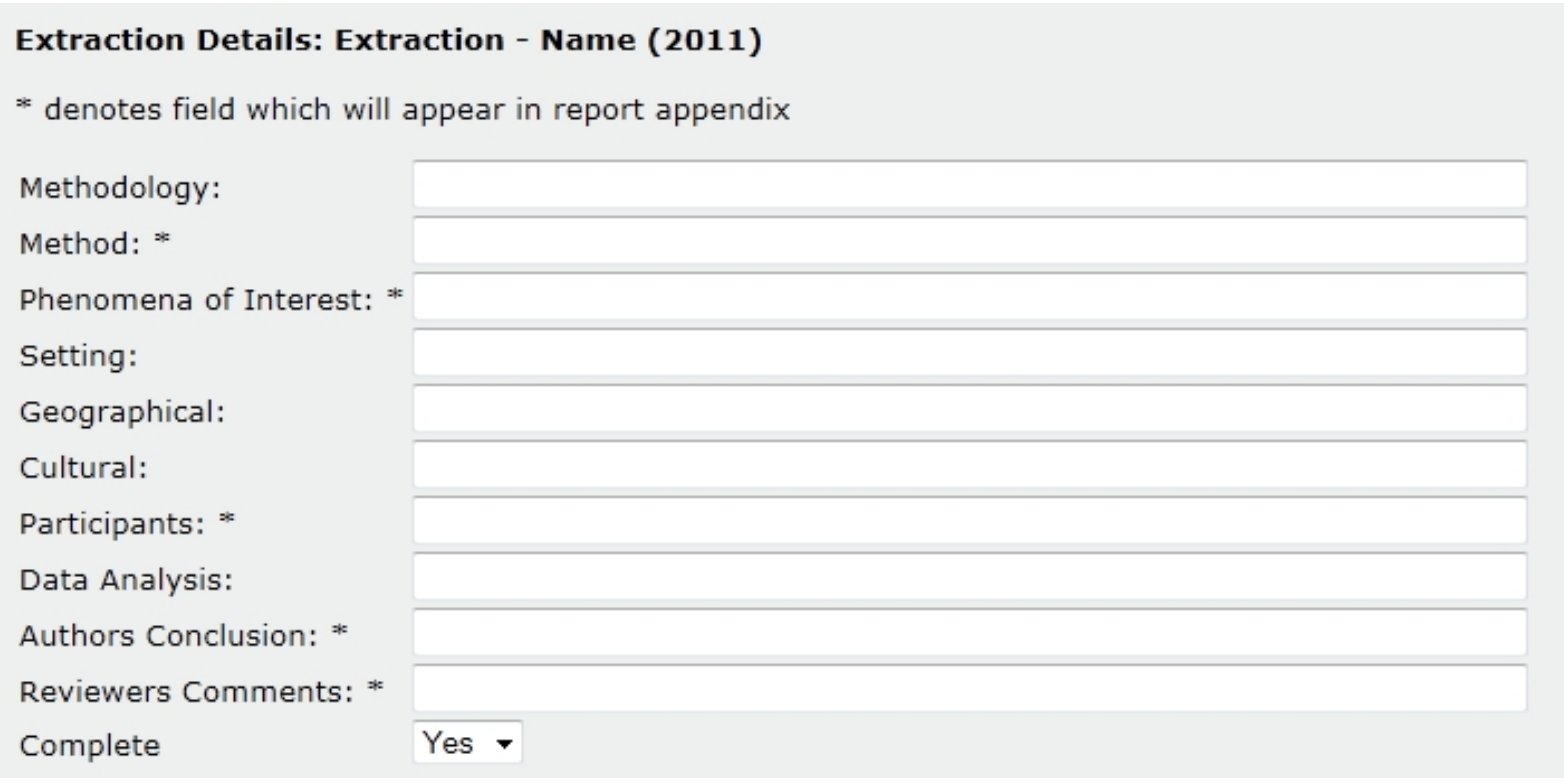

\section{Appendix 4: Table of Included studies}

\begin{tabular}{|c|c|c|c|}
\hline Study & Location & Design & Findings \\
\hline $\begin{array}{l}\text { Hasson F, Kernohan WG, } \\
\text { Waldron M, Whittaker E, } \\
\text { Mclaughlin D. }\end{array}$ & Ireland & $\begin{array}{l}\text { Descriptive qualitative } \\
\text { study of } 14 \text { nurses using } \\
\text { focus groups that were } \\
\text { recorded }\end{array}$ & $\begin{array}{l}\text { Clinical leadership programs are } \\
\text { often hindered by the organisations } \\
\text { barriers }\end{array}$ \\
\hline $\begin{array}{l}\text { Capezuti E, Taylor J, Brown } \\
\text { H, Strothersiii H, Ouslander } \\
\text { J. }\end{array}$ & USA & $\begin{array}{l}\text { Employing qualitative } \\
\text { methods of recorded logs, } \\
\text { interactions and } \\
\text { interviews }\end{array}$ & $\begin{array}{l}\text { Clinical leaders are often hindered } \\
\text { by organisational barriers }\end{array}$ \\
\hline Juthberg C, Sundin K. & Sweden & $\begin{array}{l}\text { Part of a stress of } \\
\text { conscience study using } \\
\text { qualitative methods for } \\
\text { interviews }\end{array}$ & $\begin{array}{l}\frac{\text { High negative experiences across }}{\text { nurses and clear stress related to }} \\
\text { conscience }\end{array}$ \\
\hline $\begin{array}{l}\text { Venturato L, Kellett U, } \\
\text { Windsor C. }\end{array}$ & Australia & $\begin{array}{l}\text { Critical hermeneutic study } \\
\text { using interview and focus } \\
\text { groups }\end{array}$ & $\begin{array}{l}\text { Nurses' experiences included } \\
\text { coping with change, searching for } \\
\text { value, conflicts in care }\end{array}$ \\
\hline $\begin{array}{l}\text { Cherry B, Ashcraft A, Owen } \\
\text { D. }\end{array}$ & USA (west Texas) & $\begin{array}{l}\text { Qualitative research using } \\
\text { semi structured } \\
\text { interviews }\end{array}$ & $\begin{array}{l}\text { Staff experience care-related } \\
\text { stress, poor communication, } \\
\text { devalued by compliance but want to } \\
\text { work in aged care }\end{array}$ \\
\hline Venturato L, Drew L. & Australia & $\begin{array}{l}\text { Exploratory study using a } \\
\text { range of qualitative } \\
\text { methods to address } \\
\text { research and focus } \\
\text { groups }\end{array}$ & $\begin{array}{l}\text { A positive and proactive } \\
\text { organisational approach had a } \\
\text { positive impact on change and the } \\
\text { nurses' experience }\end{array}$ \\
\hline $\begin{array}{l}\text { Karlsson I, Ekman SL, } \\
\text { Fagerberg I. }\end{array}$ & Sweden & $\begin{array}{l}\text { Qualitative with latent } \\
\text { context analysis of } \\
\text { recordings in interviews }\end{array}$ & $\begin{array}{l}\text { RNs experience paradoxical } \\
\text { feelings of being valued and } \\
\text { devalued, frustrated and } \\
\text { underestimated }\end{array}$ \\
\hline $\begin{array}{l}\text { Carryer J, O. Hansen C, } \\
\text { Blakely J. }\end{array}$ & New Zealand & $\begin{array}{l}\text { Qualitative questionnaires } \\
\text { that were followed up with } \\
\text { interviews and focus } \\
\text { groups to gain deeper } \\
\text { understanding }\end{array}$ & $\begin{array}{l}\text { RNs experience a lack of } \\
\text { education, experience low job } \\
\text { satisfaction, have issues regarding } \\
\text { accountability, and feel devalued by } \\
\text { colleagues and supporters. }\end{array}$ \\
\hline
\end{tabular}




\begin{tabular}{|c|c|c|c|}
\hline Study/paper & method & design & Reason for exclusion \\
\hline $\begin{array}{l}\text { Tonuma, M. and Winbolt, } \\
\text { M. (2000) }\end{array}$ & $\begin{array}{l}\text { Implementation } \\
\text { process for change } \\
\text { in an RACF }\end{array}$ & $\begin{array}{l}\text { Discussion paper of } \\
\text { outcomes in a project }\end{array}$ & Not a qualitative study \\
\hline $\begin{array}{l}\text { Tourangeau, A.., } \\
\text { Cranley, L., Spence } \\
\text { Lashinger, H. K. and } \\
\text { Pachis, J. (2010) }\end{array}$ & $\begin{array}{l}\text { Survey and data } \\
\text { collection of } 675 \\
\text { staff from RACF }\end{array}$ & $\begin{array}{l}\text { Qualitative and } \\
\text { quantitative with } \\
\text { literature review }\end{array}$ & Not a qualitative study \\
\hline $\begin{array}{l}\text { Donoghue, C. Castle, N, } \\
\text { G.(2009) }\end{array}$ & $\begin{array}{l}\text { Data analysis of } \\
\text { survey conducted in } \\
2005\end{array}$ & $\begin{array}{l}\text { Using a general linear } \\
\text { model (GLM) }\end{array}$ & Not a qualitative study \\
\hline $\begin{array}{l}\text { Aroskar AM, G. Good, C. } \\
\text { (2004) }\end{array}$ & $\begin{array}{l}\text { Literature review and } \\
\text { discussion of } \\
\text { findings }\end{array}$ & Discussion paper & $\begin{array}{l}\text { Not a qualitative study } \\
\text { Discussion paper } \\
\text { Not RACF } \\
\text { General nursing domain }\end{array}$ \\
\hline Shanley, C. (2007) & $\begin{array}{l}\text { Literature review and } \\
\text { discussion of } \\
\text { findings }\end{array}$ & Discussion paper & $\begin{array}{l}\text { Not a qualitative study } \\
\text { Discussion paper } \\
\text { Not RACF-specific } \\
\text { General nursing domain }\end{array}$ \\
\hline $\begin{array}{l}\text { Rubin, G., Balaji, RV. and } \\
\text { Barcikowski, R. (2009) }\end{array}$ & $\begin{array}{l}\text { Survey and data } \\
\text { collection of } 21 \\
\text { nursing staff from } \\
\text { RACF }\end{array}$ & $\begin{array}{l}\text { Qualitative and } \\
\text { quantitative with RCT } \\
\text { and RCG }\end{array}$ & $\begin{array}{l}\text { Not a qualitative study } \\
\text { Has quantitative methods in design }\end{array}$ \\
\hline $\begin{array}{l}\text { Flemming , ML. Kayser- } \\
\text { Jones, J. (2008) }\end{array}$ & $\begin{array}{l}\text { Ethnographic study } \\
\text { of the directors of } \\
\text { nursing }\end{array}$ & $\begin{array}{l}\text { Qualitative } \\
\text { ethnography }\end{array}$ & $\begin{array}{l}\text { General nursing environment without } \\
\text { specific RACF focus }\end{array}$ \\
\hline $\begin{array}{l}\text { Anderson MA, Slater M, } \\
\text { Aird T, Haslam WB. } \\
\text { (1993) }\end{array}$ & Discussion paper & Discussion paper & $\begin{array}{l}\text { Not qualitative and publication date did not } \\
\text { meet inclusion criteria }\end{array}$ \\
\hline $\begin{array}{l}\text { McGilton, KS. Hall, LMG. } \\
\text { Boscart, V. Brown, M } \\
\text { (2007) }\end{array}$ & $\begin{array}{l}\text { Question sheets and } \\
\text { survey data analysis } \\
\text { across } 10 \text { RACFs }\end{array}$ & $\begin{array}{l}\text { Quantitative and } \\
\text { discussion }\end{array}$ & Not a qualitative study \\
\hline $\begin{array}{l}\text { Hertzberg, A., Ekman, S.- } \\
\text { L. and Axelsson, K. } \\
\text { (2003) }\end{array}$ & $\begin{array}{l}\text { Semi-structured } \\
\text { interviews guided by } \\
\text { written questions }\end{array}$ & $\begin{array}{l}\text { Qualitative explorative } \\
\text { design }\end{array}$ & $\begin{array}{l}\text { Not meeting inclusion criteria for subject } \\
\text { matter of participants }\end{array}$ \\
\hline $\begin{array}{l}\text { McCormack, B. Wright, } \\
\text { J.(1999) }\end{array}$ & $\begin{array}{l}\text { Case management } \\
\text { project development } \\
\text { Documentation audit }\end{array}$ & $\begin{array}{l}\text { Practice development } \\
\text { project } \\
\text { Data analysis }\end{array}$ & $\begin{array}{l}\text { Hospital-based project implementation that } \\
\text { did not meet the appraisal criteria }\end{array}$ \\
\hline
\end{tabular}




\begin{tabular}{|c|c|c|c|}
\hline $\begin{array}{l}\text { Anonymous article } \\
\text { International column } \\
\text { Applied Nursing } \\
\text { Research }\end{array}$ & Discussion paper & Discussion paper & Not a qualitative study \\
\hline $\begin{array}{l}\text { Kowalski, K. Bradley, K. } \\
\text { Pappas, S. (2006) }\end{array}$ & Discussion paper & Discussion paper & Not a qualitative study \\
\hline $\begin{array}{l}\text { Nay, R. Garratt, S. Koch, } \\
\text { S. (1999) }\end{array}$ & Discussion paper & Discussion paper & Not a qualitative study \\
\hline $\begin{array}{l}\text { Dumas, LG. Blanks, C. } \\
\text { Palmer-Erbs, V. Portnoy, } \\
\text { FL }\end{array}$ & Discussion paper & Discussion paper & Not a qualitative study \\
\hline Moiden, N. (2002) & Discussion paper & Discussion paper & Not a qualitative study \\
\hline Dorson, P. (2006) & Discussion paper & Discussion paper & Not a qualitative study \\
\hline Eliopoulos, C. (1999) & Discussion paper & Discussion paper & Not a qualitative study \\
\hline $\begin{array}{l}\text { Jeong, SY-S. Keatinge, } \\
\text { D. (2004) }\end{array}$ & Discussion paper & $\begin{array}{l}\text { Qualitative and } \\
\text { quantitative design } \\
\text { Discussion paper } \\
\text { Consisted of a } \\
\text { documentation review } \\
\text { and data analysis } \\
\end{array}$ & $\begin{array}{l}\text { Not a qualitative study } \\
\text { Consisted of a documentation review and } \\
\text { data analysis }\end{array}$ \\
\hline $\begin{array}{l}\text { Fussell, B. Mclnerney, F. } \\
\text { Patterson, E. (2009) }\end{array}$ & $\begin{array}{l}\text { Case study } \\
\text { approach }\end{array}$ & Case study approach & $\begin{array}{l}\text { Not qualitative and participants did not meet } \\
\text { the inclusion criteria }\end{array}$ \\
\hline $\begin{array}{l}\text { Cheek, J. Ballantyne, A. } \\
\text { Jones, J. Roder-Allen, G. } \\
\text { and Kitto, S. (2003) }\end{array}$ & $\begin{array}{l}\text { Exploratory } \\
\text { Qualitative study of } 3 \\
\text { groups in stages }\end{array}$ & $\begin{array}{l}\text { Qualitative and data } \\
\text { analysis }\end{array}$ & $\begin{array}{l}\text { Not a qualitative study on the experiences } \\
\text { of clinical leadership }\end{array}$ \\
\hline Clegg, A.(2000) & Discussion paper & Discussion paper & $\begin{array}{l}\text { Not a qualitative study on the experiences } \\
\text { of clinical leadership for RACF RN }\end{array}$ \\
\hline
\end{tabular}




\section{$\underline{\text { References }}$}

1. Nay R. RECRUITMENT AND RETENTION OF NURSES IN AGED CARE. Australian Nursing Journal. [Article]. 1998;5(8):30-35.

2. Aberdeen S, Angus J. A Systematic Approach to Curricula Development for Aged-Care Leadership. Educational Gerontology. 2005;31(6):481-97.

3. Caruana E. Comprehensive systematic review of evidence on developing and sustaining nursing leadership that fosters a healthy work environment in health care. Journal of Advanced Nursing. [Article]. 2008;62(6):653-4.

4. Fussell B, Mclnerney F, Patterson E. Experiences of graduate registered nurses in aged care: a case study. Contemporary Nurse: A Journal for the Australian Nursing Profession. 2009;33(2):210-23.

5. Nay RG, S. Koch, M. Challenges for Australian Nursing in the International Year of the older person. Geriatric nursing. [journal]. 1999 1999;20(1):14-7.

6. Moiden N. Leadership in the elderly care home sector. Nursing Management - UK. 2002;9(8):24-8.

7. Jeong SY-S, Keatinge D. Innovative leadership and management in a nursing home. Journal of Nursing Management. [Article]. 2004;12(6):445-51.

8. Pearson A, Koch S, Ward C, Andrews C, \& Tucker A. . Australian aged care nursing: A critical review of education, training, recruitment and retention in residential and community settings. Canberra: Department of Education, Science and Training. 2001.

9. Pearson A, Laschinger H, Porritt K, Jordan Z, Tucker D, Long L. Comprehensive systematic review of evidence on developing and sustaining nursing leadership that fosters a healthy work environment in healthcare. International Journal of Evidence-Based Healthcare. 2007;5(2):208-53.

10. Jeon Y-HM, Teri Chenoweth, Lynn. Leadership and management in the aged care sector: A narrative synthesis. Australasian Journal on Ageing. 2010;29(2):54-60.

11. Pearson AL, H. Porritt. K. Jordan, Z. Tucker, D. Long, L. . Comprehensive systematic review of evidence on developing and sustaining nursing leadership that fosters a healthy work environment in healthcare. Int J Evid Based Healthc. 2007; 5:45.

12. Kowalski K, Bradley K, Pappas S. Nurse retention, leadership, and the Toyota System Model: Building leaders and problem solvers for better patient care. Nurse Leader. 2006;4(6):46-51.

13. Chenoweth L, Jeon $\mathrm{Y}-\mathrm{H}$, Merlyn $\mathrm{T}$, Brodaty $\mathrm{H}$. A systematic review of what factors attract and retain nurses in aged and dementia care. Journal of Clinical Nursing. 2010;19(1-2):156-67. 
14. Dumas LG, Blanks C, Palmer-Erbs V, Portnoy FL. Leadership in Nursing Homes--2009: Challenges for Change in Difficult Times. Nursing Clinics of North America. 2009;44(2):169-78.

15. Carryer J OHC, Blakely J. Experiences of nursing in older care facilities in New Zearland. Australian Healty Review. [journal]. 2010 2010;34(34):11-7.

16. Oulton JA. The Global Nursing Shortage: An Overview of Issues and Actions. Policy, Politics, \& Nursing Practice. 2006 August 1, 2006;7(3 suppl):34S-9S.

17. Janiszewski Goodin H. The nursing shortage in the United States of America: an integrative review of the literature. Journal of Advanced Nursing. 2003;43(4):335-43.

18. Francis-Felsen LC, Coward RT, Hogan TL, Duncan RP, Hilker MA, Horne C. Factors Influencing Intentions of Nursing Personnel to Leave Employment in Long-Term Care Settings. Journal of Applied Gerontology. 1996 December 1, 1996;15(4):450-70.

19. Venturato $\mathrm{L} K \mathrm{KU}$, Windsor C. Nurses experience of practice and reform in long term aged care in Australia: Implications for the retention of nursing personnel. Journal of Nursing Management. [journal]. 2007 2007;2007(15):4-11.

20. Karlsson I, Ekman SL, Fagerberg I. A difficult mission to work as a nurse in a residential care home some registered nurses' experiences of their work situation. Scandinavian Journal of Caring Sciences. 2009;23(2):265-73.

21. Capezuti E, Taylor J, Brown H, Strothersiii H, Ouslander J. Challenges to implementing an APNfacilitated falls management program in long-term care. Applied Nursing Research. 2007;20(1):2-9.

22. Hasson F, Kernohan WG, Waldron M, Whittaker E, Mclaughlin D. The palliative care link nurse role in nursing homes: barriers and facilitators. Journal of Advanced Nursing. 2008;64(3):233-42.

23. Venturato L DL. Beyond Doing: Supporting clinical leadership and nursing practice in aged care through innovative models of care. Contemporary Nurse. 2010;35(2):157-70.

24. Cherry B, Ashcraft A, Owen D. Perceptions of Job Satisfaction and the Regulatory Environment Among Nurse Aides and Charge Nurses in Long-Term Care. Geriatric Nursing. 2007;28(3):183-92.

25. Juthberg C, Sundin K. Registered nurses' and nurse assistants' lived experience of troubled conscience in their work in elderly care-A phenomenological hermeneutic study. International Journal of Nursing Studies. 2010;47(1):20-9.

26. <experience of regist nurse aged care.pdf>.

27. Webster. Websters New World College Dictionary [Dictionary definition]. Cleveland, Ohio: Wiley \& Sons publishing; 2010 [cited 2010 18, May 2010]. Available from: "http://www.yourdictionary.com/registered-nurse">registered. 
